\title{
Relocation of Earthquakes that Occurred Beneath Parkfield Region of California using VELHYPO
}

\author{
${ }^{1}$ Abel U. Osagie, ${ }^{2}$ Woohan Kim \\ ${ }^{I}$ Department of Physics, University of Abuja, Abuja, Nigeria \\ ${ }^{2}$ Department of Earth and Environmental Sciences, Gyeongsang National University, Jinju 660-701, Korea.
}

\begin{abstract}
When only direct-waves are inadequate, different combinations of both direct-and refracted-waves are used to determine hypocentral parameters of local earthquakes. Compared with only direct-waves, the addition of refracted-waves tends to increase errors of hypocentral parameters. This is true especially when the velocity structure of the region under investigation is not known. We use an accurate and fast algorithm to determine the hypocentral parameters based on an optimum 1-D velocity model yielding a minimum misfit error in media with multiple refracted-waves as first arrivals. Using the algorithm, we relocated earthquakes that occurred beneath the Parkfield region of California during the period between January 2000 and December 2000. The shallow part of the velocity model used in the study area has high velocity contrast among layers. Therefore, refracted-waves are recorded as first-arrival phases at most stations around the region for events of shallow focal depths (less than $3 \mathrm{~km}$ ). The study area covers the transition between the creeping segment of San Andreas Fault (SAF) to the northwest and the locked segment to the southeast. Accuracy test for the algorithm was conducted using some reference models. We compare the inverted hypocentral parameters with those determined by previous studies using HYPOINVERSE and the HypoDD. The epicentral distributions of the three methods show a close relationship with the regional fault distribution. However, compared to HypoDD, the epicentral distribution of HYPOINVERSE shifted slightly along the fault lines while the epicentral distribution of VELHYPO moved further in the same direction. The result of VELHYPO suggests that the dip of San Andreas Fault is 6-10 $0^{\circ} W$ while the results of HPOINVERSE and HypoDD suggest that the dip of San Andreas Fault is nearly vertical and/or 3-7 $7^{\circ}$ E. This study supports the result of previous studies that San Andreas Fault is nonvertical but dips to southwest as part of a possible propeller-shape.
\end{abstract}

Keywords: Direct waves and Refracted-waves, Algorithm, Parkfield, Relocate Earthquakes, San Andreas Fault, SW dip, support propeller-shape.

\section{Introduction}

Reliable determination of the hypocentral parameters (latitude, longitude focal depth and origin time) has been one of the basic tools in earthquake seismology. It provides initial insight into observed seismicity and faults or subsurface structures responsible for the observations. Unfortunately, the precision of locations is affected by limitations imposed by factors, which among others include; data quality (i.e., accuracy of the arrival times, the discernible seismic phases, signal-noise- ratio, etc.), station distribution, prior information of the velocity structure of the area, and most importantly, the algorithm used for locating the earthquakes. Even with dense and well distributed station coverage as well as excellent quality data, techniques (algorithm) to determine hypocentral parameters still fall short of very accurate results because precise velocity structure of the region under investigation is not well known. There are usually tradeoffs between earthquake locations and velocity structure. Although the earth's velocity structure may have both vertical and lateral variations, in many cases a simplified 1-D velocity model can produce results that are consistent with observed data. Hence the need to develop an approximate 1-D velocity model for hypocenter inversions.

The Parkfield section of San Andreas Fault (SAF) is bounded on the northwest by a 150-km-long creeping section, where numerous small earthquakes occur, and on the southeast by hundreds of kilometers of locked fault that last broke in the great $1857 M_{w}=7.9$ Fort Tejon earthquake (Sieh, 1978). The study area is bordered by latitude $35^{\circ} 40^{\prime} \mathrm{N}-36^{\circ} 20^{\prime} \mathrm{N}$ and longitude $120^{\circ} 12^{\prime} \mathrm{W}-120^{\circ} 54^{\prime} \mathrm{W}$ (about 80 square kilometers). The U.S. Geological Survey (USGS) 1-D velocity model beneath Parkfield area suggests that refracted-waves from multiple boundaries dominate as first-arrivals to most recording stations in the region due to large velocity contrasts among the first few layers. This is true especially for shallow focal depth events. Unfortunately, refracted-waves show more sensitivity to difference in velocity structure between the true and used models. Therefore, refracted-waves have high possibility to increase errors in determination of hypocentral parameters.

In this study, we introduce an accurate and fast scheme to determine the hypocentral parameters based on an optimum 1-D velocity model yielding a minimum misfit error in media with multiple refracted-waves as first arrivals. To get an optimum velocity model, the algorithm searches iteratively by shifting an initial reference model within a prescribed range. We test the accuracy of hypocentral parameters using synthetic data. We then 
apply the algorithm to relocate earthquakes that occurred around Parkfield, California during the period from January 2000 to December 2000 . We finally compare the result of this study with those obtained by HYPOINVERSE and HypoDD.

\section{i. Geology and Tectonic setting of the Study Area}

\section{Literature Review}

The Parkfield section of the San Andreas Fault (SAF) spans the transition between the creeping segment of the fault to the northwest and the locked segment to the southeast, which last broke in the great 1857 Fort Tejon earthquake (Sieh 1978). It is reported that the geology of the area is dominated by the SAF system and has three other faults which are believed to play varying roles in the local geology (Sims, 1990; Sims and Hamilton, 1990). The faults include; the Gold Hill Fault immediately northeast of the SAF mapped as a southwest dipping thrust (Sims, 1990; Sims and Hamilton, 1990), the Southwest Fractured Zone immediately southwest of the SAF (Brown, et al., 1967), and the White Canyon Fault in the Cholame Valley several kilometers further to the south of SAF (Sims and Hamilton, 1990). The area is of interest because of the very different basement rocks juxtaposed by the fault. The rock types in this section are generally characterized by faster materials (Salinian granitic rocks) covered by a maximum of $2 \mathrm{~km}$ of Tertiary and Quaternary marine and non-marine sediments and volcanics on the southwest side of the fault, and slower material (Franciscan rocks and Great Valley sequence) on the northeast side (Walter \& Mooney 1982; Lees \& Malin 1990). At least seven earthquakes of M6 occurred on the Parkfield segment since 1857, with the most recent on 2004 September 28 (Bakun et al. 2005). The quasi-periodicity of the previous six events led to the deployment of many seismic and other instruments as part of the Parkfield Earthquake Prediction Experiment (Bakun \& Lindh 1985). Velocity models there show high $v_{\mathrm{p}} / v_{\mathrm{s}}$ ratio along the fault near the surface and at depth within the fault zone, and a pronounced strong vertical velocity gradient in the upper $2 \mathrm{~km}$ of the section (Michelini and McEvilly, 1991; EberhartPhillips and Michael, 1993). A total of 97 stations recorded at least one data. The station distribution is shown in figure 1 and the list of stations and their corrections is shown in Appendix I.

\section{ii. Existing Techniques}

Some conventional techniques for determining hypocentral parameters include HYPO-71 (Lee and Lahr, 1975), HYPOINVERSE (Klein, 1978), HYPOELLIPSE (Lahr, 1980), VELEST (Kissling et al., 1994), HYPOSAT (Schweitzer, 2001). Hypocentral inversion methods are performed to minimize residuals between calculated and observed traveltimes. The conventional methods calculate traveltimes based on fixed velocity models. However, these conventional methods which are based on fixed velocity models can yield correct hypocentral parameters only if true velocity structure is implemented. The inverted hypocentral parameters can vary by the implemented velocity model (Lomnitz, 2006). The consequence of such approach yields errors to determined hypocentral parameters. To avoid errors due to the implementation of incorrect velocity models, hypocentral inversion methods have been developed to determine both the hypocentral parameters and velocity structures simultaneously (e.g., Pavlis and Booker, 1983; Thurber, 1985, 1992; Kissling et al., 1994), which were found to be useful for analysis of multiple events. In these methods, seismic velocities of each layer are considered to be additional unknown parameters. However, such methods are not only expensive in computation, but may also yield hypocentral parameters and velocity structures that tend to vary with the initial velocity models implemented. Thus, it may be required to implement initial velocity models that are close to the actual velocity structures for determination of accurate parameters. However, the implementation of velocity models close to the actual velocity structures is somewhat difficult because 1-D and 2-D velocity models inherently have limitations in representation of the actual 3-D Earth structures.

Recently, a double-difference method based on differential traveltimes (hypoDD) was proposed. The method was found to be useful for analysis of clustered events (Waldhauser and Ellsworth, 2000). The method determines the relative locations of the clustered events from traveltime differences among pairs of waveforms that are estimated precisely with the help of waveform cross-correlation. However, the hypoDD is supposed to implement initial hypocentral parameters that are calculated by usual conventional methods that yield the hypocentral parameters depending on the reference velocity models implemented. Thus, the hypocentral parameters from hypoDD are inherently dependent on the reference velocity models. Also, the hypoDD can be applicable only to clustered events.

Therefore, it is required to determine hypocentral parameters accurately with little dependence on a given or initial velocity model. Such methods may be particularly useful for regions of which velocity structures are poorly known. Kim et al. (2006) proposed a full inversion method based on a genetic algorithm, GA-MHYPO, which determine both a best-fitting velocity model and hypocentral parameters. Here, the best-fitting model is not the actual velocity structure, but an optimum velocity model yielding the minimum traveltime residual. It was found that the GA-MHYPO yields hypocentral parameters with higher accuracy than conventional methods, 
and is rarely dependent on the initial velocity model (Hahm et al., 2007). However, GA-MHYPO suffers from high computational costs due to iterative velocity refinement based on the genetic algorithm, which hinders prompt analysis in practical application.

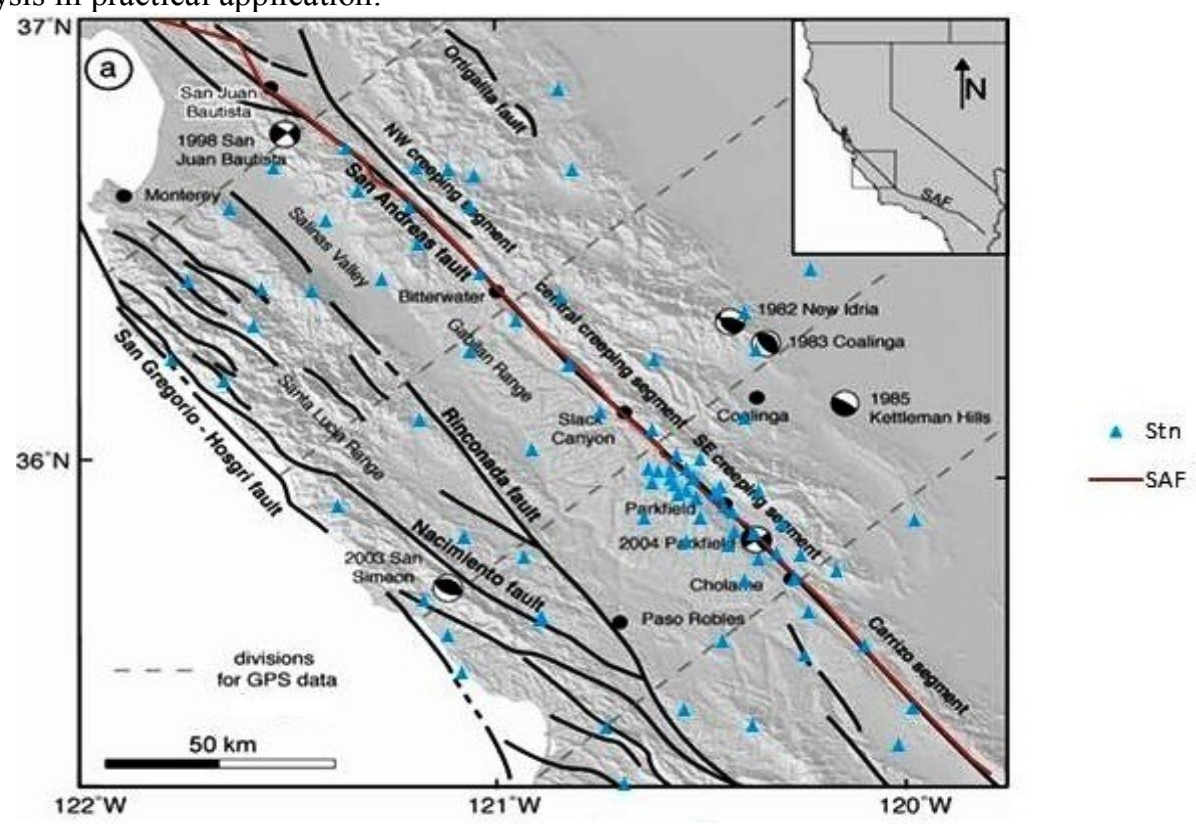

Figure 1 Distribution of 97 stations and the San Andreas Fault line around Parkfield region, California. Map is courtesy Titus et al, 2010.

\section{i. $\quad$ Model Refinement}

\section{Model Refinement and Velocity Model}

We use an algorithm to search an optimum 1-D velocity model yielding minimum misfit errors for hypocentral inversions. The algorithm is based on a weighted average P-wave velocity in a medium between source and receiver. The algorithm iteratively selects the best-fitting average velocity from the results of grid searching methods within a prescribed range. We search an optimum velocity model by modifying the velocities in each layer of given velocity model that has a constant number of layers and constant thicknesses of layers. An optimum velocity model is determined with an idea that a velocity model with a proper average velocity and velocity gradient reproduce synthetic traveltimes that are close to the observed traveltimes with sufficient level of accuracy. Here, the implemented average velocity may be close to that of actual structure. First, we determine a semi-optimum 1-D $P$ and $S$ velocity model. We prepare a set of $P$ velocity models that are shifted with a constant interval from the given $P$ velocity model:

$$
\alpha_{i}^{\mathrm{n}}=\alpha_{i}^{0}+\mathrm{n} \Delta \alpha
$$

where $\Delta \alpha$ is a constant velocity interval, $\mathrm{n}$ is an integer, $\alpha_{\mathrm{i}}^{0}$ is the initial $P$ velocity for the $i^{\text {th }}$ layer, and $\alpha_{i}^{\mathrm{n}}$ is the n times shifted $P$ velocity for the $i^{\text {th }}$ layer. Here, the $S$ velocity models can be prepared subsequently from the $P$ velocity model and a given $v_{p} / v_{s}$ ratio. We can vary $v_{p} / v_{s}$ ratio within a fixed window typical of the $v_{p} / v_{s}$ ratio in the crust. In this study, we scale the $P$ arrival times by a factor of $1 / \sqrt{3}$ due to insufficient $S$ arrival times in many of the events.

The optimum $P$ velocity model is determined by iterative refinement of velocity model with consecutive implementation of smaller $\Delta \alpha$ in equation (1). We prepare a set of $\Delta \alpha$ that is composed of $0.1,0.01,0.001$, and $0.0001 \mathrm{~km} / \mathrm{s}$. In every refinement of velocity, we improve the accuracy of the velocities to higher places of decimals. For instance, when we refine the velocity model with $\Delta \alpha$ of $0.01 \mathrm{~km} / \mathrm{s}$, we improve the accuracy of the velocities to 2 places of decimals. In this case, the optimum velocity model to 1 place of decimals is used as the reference velocity model in determining an optimum velocity model to 2 places of decimals. The optimum velocities to 2 places of decimals are searched in ranges between -0.05 to $0.04 \mathrm{~km} / \mathrm{s}$ with respect to the optimum velocities to 1 place of decimals. Such consecutive refinement of velocity models with application of smaller $\Delta \alpha$ allows us to reduce computational time effectively. Figure 2 presents an example of the model refinement 
scheme for a velocity model with a weighted average velocity that is larger by $0.1785 \mathrm{~km} / \mathrm{s}$ than the reference velocity model applied. In the first round of model refinement, the search to 1 place of decimals is between -0.6 and $0.6 \mathrm{~km} / \mathrm{s}$ with respect to the reference velocity at $\Delta \alpha$ of $0.1 \mathrm{~km} / \mathrm{s}$. The second round is to 2 places decimals varying between -0.05 and $0.04 \mathrm{~km} / \mathrm{s}$ with $\Delta \alpha$ of $0.01 \mathrm{~km} / \mathrm{s}$. The optimum velocity to 3 places of decimals is found at a velocity difference of $0.179 \mathrm{~km} / \mathrm{s}$ in the third round.

$-0.7,-0.6,-0.5,-0.4,-0.3,-0.2,-0.1,0 ., 0.1,0.2,0.3,0.4,0.5,0.6,0.7$
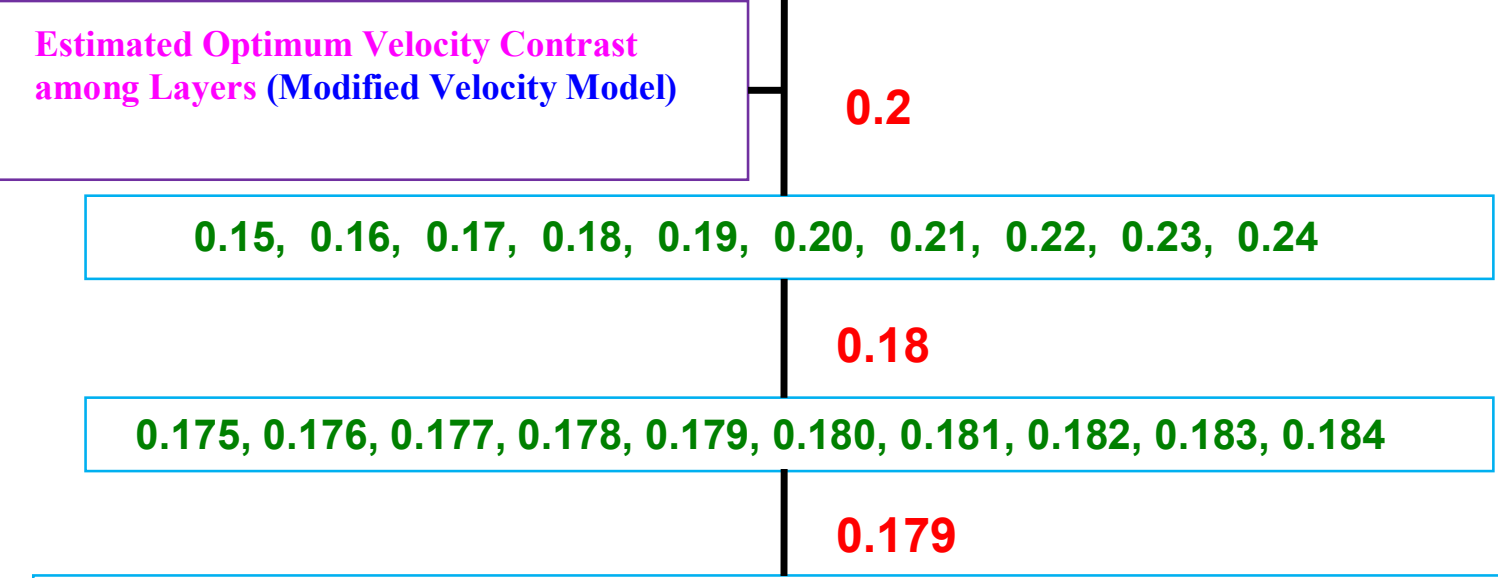

$0.1785,0.1786,0.1787,0.1788,0.1789,0.1790,0.1791,0.1792,0.1793,0.1794$

\begin{tabular}{|c|c|}
\hline & 0.1785 \\
\hline STOP \\
\hline
\end{tabular}

Figure 2 Example of the model refinement scheme for a velocity model with a weighted average velocity that is larger by $0.1785 \mathrm{~km} / \mathrm{s}$ than the reference velocity model applied.

\section{ii. Velocity Model}

Researches in the past have led to the establishment of different velocity models across Northern California. The U.S. Geological Survey (USGS) P-wave velocity model for Parkfield region is used as the true velocity model to generate synthetic data. The model is composed of nine layers with irregular intervals between boundaries consisting of a $0.25 \mathrm{~km}$-thick top layer with a relatively low P- and S-wave velocity and a high velocity contrast across the second and the third boundaries (Figure 3; Table 1). We apply the algorithm to test the accuracy of inverted hypocentral parameters. We also check the dependency of inverted hypocentral parameters on the implemented velocity models. Validation tests are conducted with synthetic data. Using the U. S. Geological Survey model, we compute cross-over distances at some selected depths for coincident epicenter. It is observed that almost all first arrivals for the first few layers are "refracted-waves". It generally appears that, for focal depths less than $4 \mathrm{~km}$, first arrivals appear to be refraction from either the bottom of the source layer or from the bottom of the first and even second layers beneath the source layer. The model suggest that only at epicentral distances greater than $85 \mathrm{~km}$ that waves refracted off the $25 \mathrm{~km}$-Moho surface become first arrivals for focal depths of less than $2.5 \mathrm{~km}$. We observe that only at focal depths greater than $6 \mathrm{~km}$ that many stations of epicentral distances less than $80 \mathrm{~km}$ record direct-wave as first arrivals. 


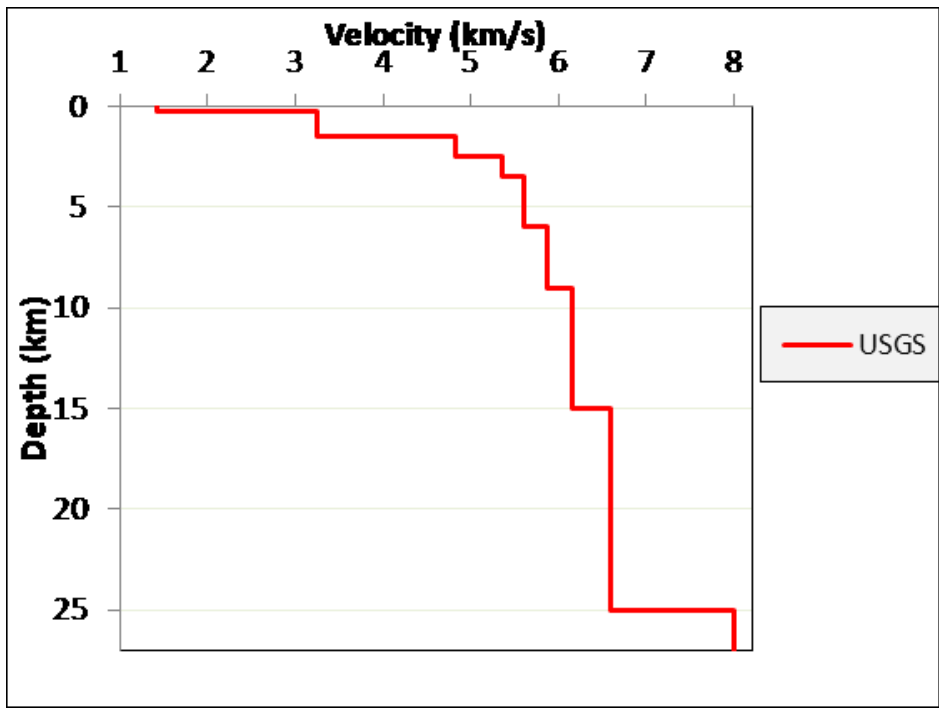

Figure 3 U.S. Geological Survey 1-D velocity model beneath Parkfield

\begin{tabular}{|ccc|}
\hline & $\begin{array}{c}\text { Depth } \\
(\mathrm{Km})\end{array}$ & $\begin{array}{c}\text { Velocity } \\
(\mathrm{Km} / \mathrm{s})\end{array}$ \\
1 & 0.00 & 1.42 \\
2 & 0.25 & 3.24 \\
3 & 1.50 & 4.82 \\
4 & 2.50 & 5.36 \\
5 & 3.50 & 5.60 \\
6 & 6.00 & 5.87 \\
7 & 9.00 & 6.15 \\
8 & 15.00 & 6.60 \\
9 & 25.00 & 8.00 \\
\hline
\end{tabular}

Table 1 USGS 1-D velocities and boundary depths beneath Parkfield

\section{Computational Result}

Conventional methods can be classified into two groups on the basis whether the velocity models are refined or not. One group of methods including HYPO-71 (Lee and Lahr, 1975), HYPOINVERSE (Klein, 1978) and HYPOELLIPSE (Lahr, 1980) determines the hypocentral parameters based on given velocity models. The other group of methods including VELEST (Kissling et al., 1994) determines hypocentral parameters along with refinement of velocity models. We implement a hypocentral inversion method based on a two-point ray tracing MHYPO (Hahm et al., 2007) of which inversion algorithm is modified from HYPO-71. The best-fitting velocities are searched using a fitness function that assesses the differences between observed and theoretical traveltimes of $P$ and $S$ waves. The determined velocities of layers may not match with the true velocities, but the estimated weighted average velocity between a source and stations should be close to the true weighted average velocity.

The accuracy of the algorithm was tested using synthetic data. The hypocentral parameters are determined more accurately using only direct waves if available number of direct waves is sufficient than using combination of direct and refracted waves. Generally, errors of hypocentral parameters are reduced when low grade (D) weighting factor is assigned to refracted-waves instead of high grade (A). This is because travel-time of refracted-wave is more sensitive than that of direct wave for velocity structure difference between true and model. Therefore, in VELHYPO computations, assigning low grade weighting factor to refracted-waves, reduces errors in inversion of hypocentral parameters when refracted-waves are combined with direct-waves as first-arrival data set.

We invert for hypocentral parameters of 333 earthquakes that occurred between January 2000 and December 2000. The data was from the Northern California Seismic Network (NCSN) catalog. A total of 97 stations recorded at least one data. Station corrections were determined by taking the average time residual for each station. This was achieved first by relocating about 300 events without station correction and taking the average residual of each station. The stations are represented by blue triangles in figure 4 . We classify the focal depths into four ranges (less than or equal to $3.5 \mathrm{~km}, 3.51-6 \mathrm{~km}, 6.01-9 \mathrm{~km}$ and greater than $9 \mathrm{~km}$ focal depths). Different colors are used to represent the various ranges of focal depths. Compared to the USGS model, the weighted average velocity between hypocenters and stations around the study region range between -23.9 and $+45.1 \%$ and increased by $16.2 \%$ on average. The weighted average velocities of 58 events are less than the USGS model while the weighted average velocities of the rest events are more than the average velocity of the USGS model. These large velocity variations may be caused by lateral (horizontal) velocity variations and 1-D velocity structure difference between the true velocity structure and the used model, especially the differences of layer number and depth boundaries among layers.

The inverted hypocentral parameters obtained in this study are compared with those determined by previous studies using HYPOINVERSE and the HypoDD. Numerical values of the results are shown in Appendix II. The relocated epicenter distribution shows a close relationship with the regional fault distribution. Figures 5a, 5b and 5c show epicentral distribution calculated by VELHYPO, HYPOINVERSE and hypoDD respectively. The perpendicular distances of the epicenters from the fault line are more disperse for VELHYPO (Fig. 5a) than HYPOINVERSE (Fig. 5b) which in turn are more disperse than HypoDD (Fig. 5c). The epicentral distribution of VELHYPO shifted slightly south-westwards when compared with HYPOINVERSE and the 
HypoDD. This favors a southwest steep dipping fault beneath the study area. On the other hand, the more linear epicentral distribution of HypoDD favors a vertical strike fault beneath the study area.

Figures $6 \mathrm{a}, 6 \mathrm{~b}$ and $6 \mathrm{c}$ show focal depth distribution with respect to latitude calculated by VELHYPO, HYPOINVERSE and hypoDD respectively. In this study, the focal depths of 92 events have less than or equal to $3.5 \mathrm{~km}$ compared with 34 events for HYPOINVERSE and 54 events for the HypoDD. 136 events between 3.51 and $6 \mathrm{~km}$ focal depths compared with compared with 158 events for HYPOINVERSE and 159 events for the HypoDD. 86 events between 6.01 and $9 \mathrm{~km}$ focal depths compared with 91 events for HYPOINVERSE and 68 events for the HypoDD. The focal depths of 19 events are greater than $9 \mathrm{~km}$ compared with 50 events for HYPOINVERSE and 52 events for the HypoDD. VELHYPO focal depths range between 0.14 and $13.7 \mathrm{~km}$, HYPOINVERSE between 0.03 and $19.19 \mathrm{~km}$ while HypoDD range between 0.11 and $16.82 \mathrm{~km}$. Most VELHYPO events of which focal depths are greater than $9 \mathrm{~km}$ occur south of latitude $36^{\circ} \mathrm{N}$ which constitute part of the locked section of the fault.

We divide the study area into two regions along latitude $36.08^{\circ}$. Figures $7(\mathrm{a}-\mathrm{f})$, show cross-section of focal depths along the perpendicular to the SAF North and South of latitude $36.08^{\circ}$ from the fault line calculated by VELHYPO, HYPOINVERSE and HypoDD. In the North of latitude $36.08^{\circ}$, events are more sparsely distributed for VELHYPO (Fig .7a) than HYPOINVERSE (Fig. 7b) which in turn are more sparsely distributed than HypoDD (Fig.7c). However, in the South of latitude $36.08^{\circ}$, events are less sparse for VELHYPO (Fig. 7d) and HYPOINVERSE (Fig.4.9e) than HypoDD (Fig. 7f). VELHYPO results show a trend where normal distances from fault line generally increase with focal depth (Fig. 7a and 7d). The trend suggests a $6-10^{\circ} \mathrm{SW}$ dip of SAF beneath the region. On the other hand, both HYPOINVERSE (Figures $7 \mathrm{~b}$ and 7e) and HypoDD (Figures $7 \mathrm{c}$ and $7 \mathrm{f}$ ) show linearly vertical and/or a dip of $3-8^{\circ} \mathrm{NE}$ of SAF. The HypoDD trend is steeper than HYPOINVERSE. The result of this study support the previous studies that propose the type of SAF in studied region is a propeller type whose dipping direction is southwest (Fuis et. al., 2012).

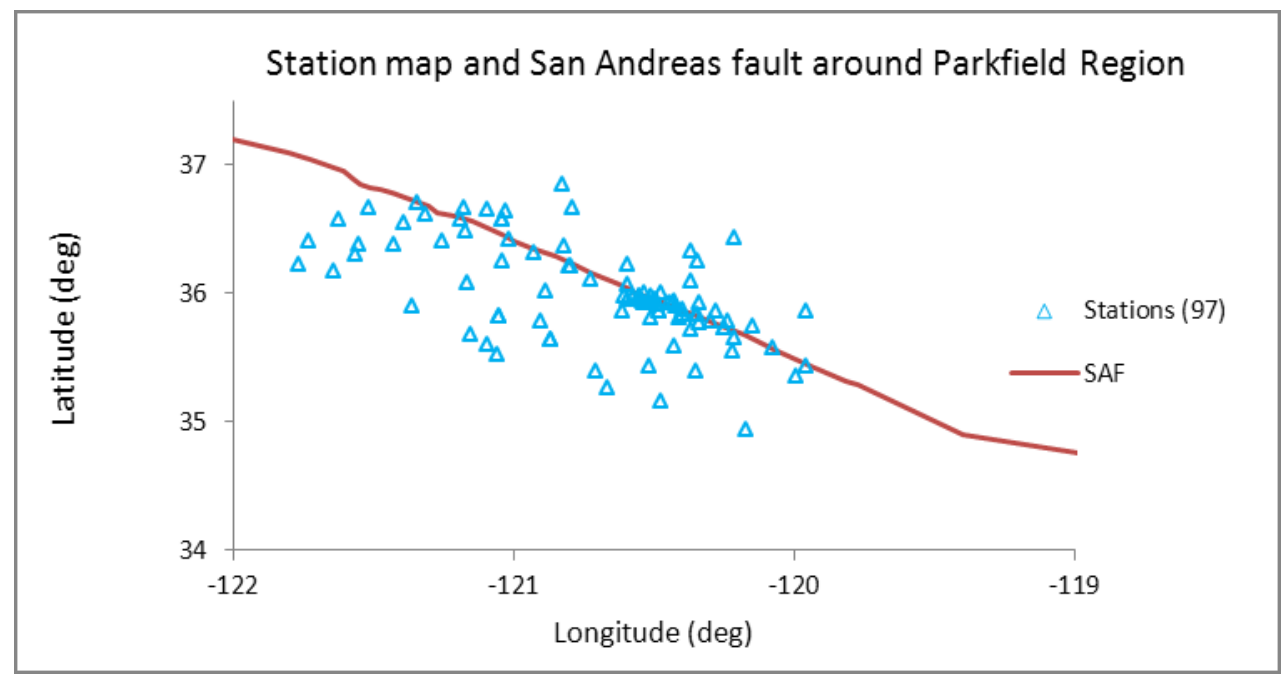

Figure 4 Station map and San Andreas Fault around Parkfield region

\section{Conclusion}

We employed VELHYPO to determine hypocentral parameters of 333 earthquakes that occurred beneath the Parkfield during the period between January and December of the year 2000. The study area covers the transition between the creeping segment of San Andreas Fault (SAF) to the northwest and the locked segment to the southeast. Hypocentral parameters inversion of the earthquakes that occurred in Parkfield region of San Andreas Fault are confined to the top $14 \mathrm{~km}$ with the bulk of the events occurring around the top $6 \mathrm{~km}$. Most events of which focal depths are greater than $9 \mathrm{~km}$ occurred below latitude $36^{\circ} \mathrm{N}$. Epicentral distribution obtained from VELHYPO shift slightly southwest when compared with the results of previous studies using HYPOINVERSE and the HypoDD. Although the events are more scattered north of latitude $36.08^{\circ}$, the result of this study shows a trend where normal distance from fault line generally increase with focal depth. The result of VELHYPO suggests that the dip of San Andreas Fault is $7-15^{\circ} \mathrm{SW}$ while those of HPOINVERSE and HypoDD suggest that the dip of San Andreas Fault is nearly vertical and/or 3-7 $\mathrm{NE}$ beneath the region. This study supports the result of previous studies that San Andreas Fault is non-vertical but dips southwest as a part of propeller-shape. 


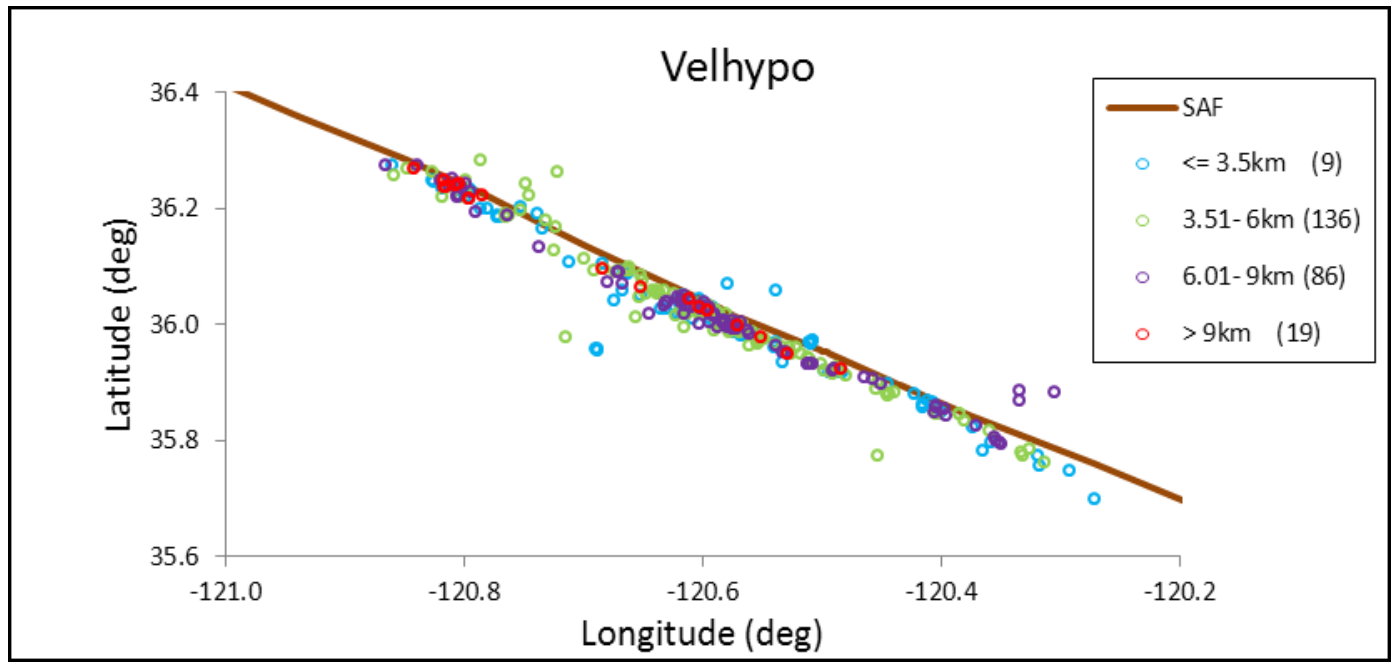

Figure 5(a) VELHYPO epicentral and depth distribution

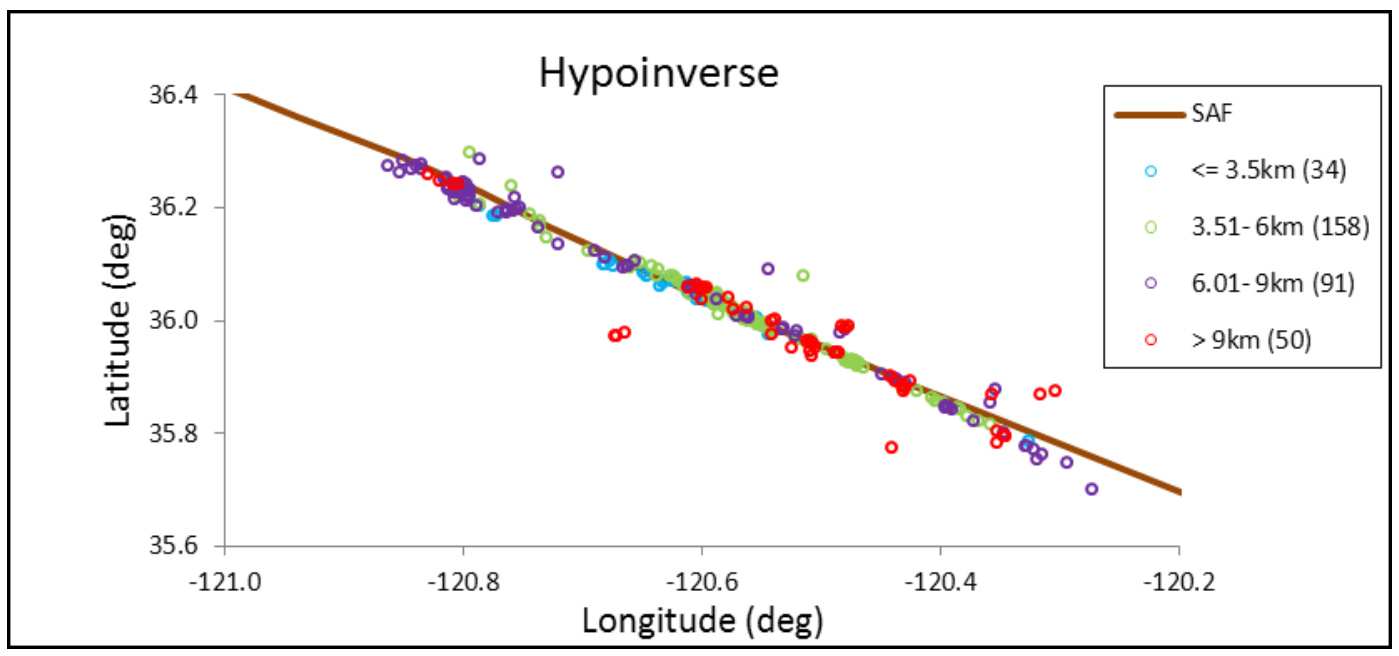

Figure 5(b) HYPOINVERSE epicentral and depth distribution

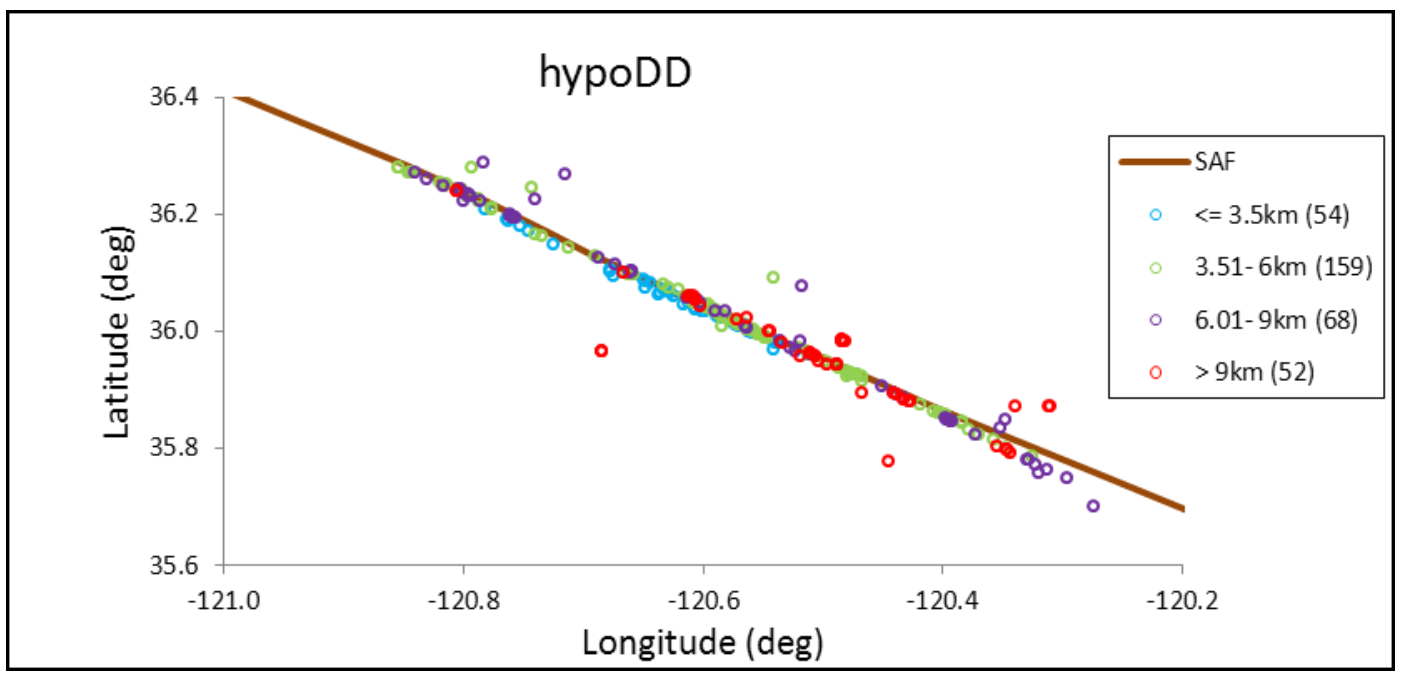

Figure 5(c) HypoDD epicentral and depth distribution 


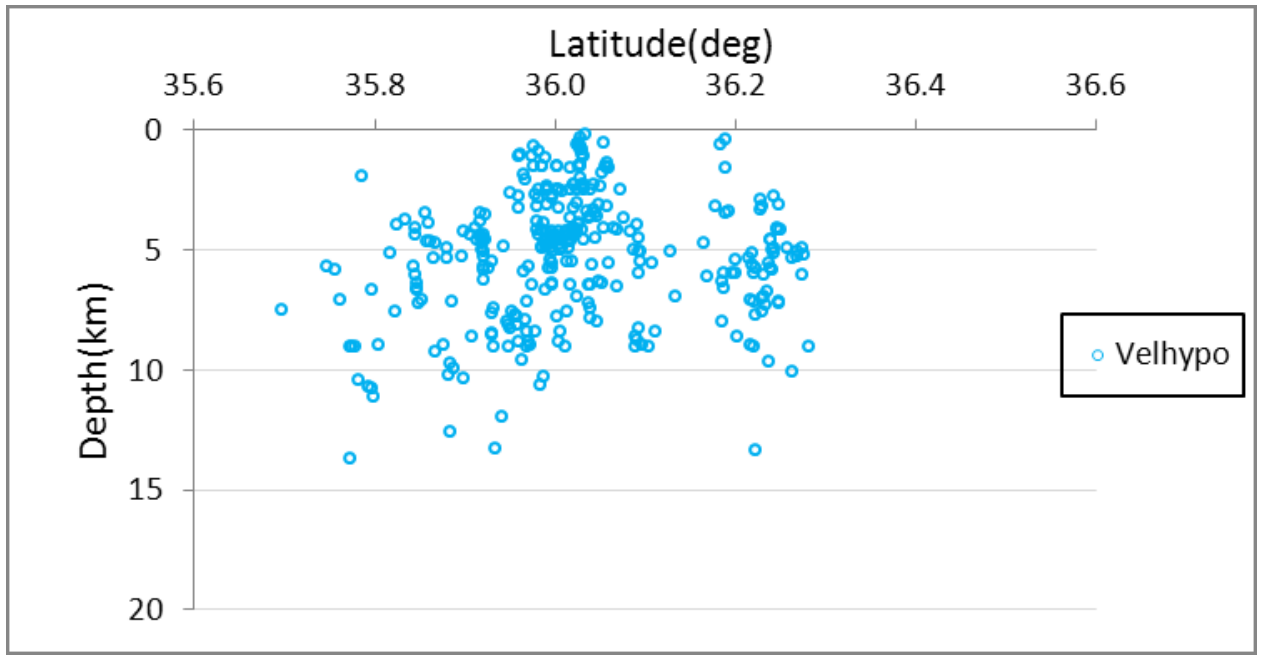

Figure 6(a) VELHYPO latitude and depth distribution

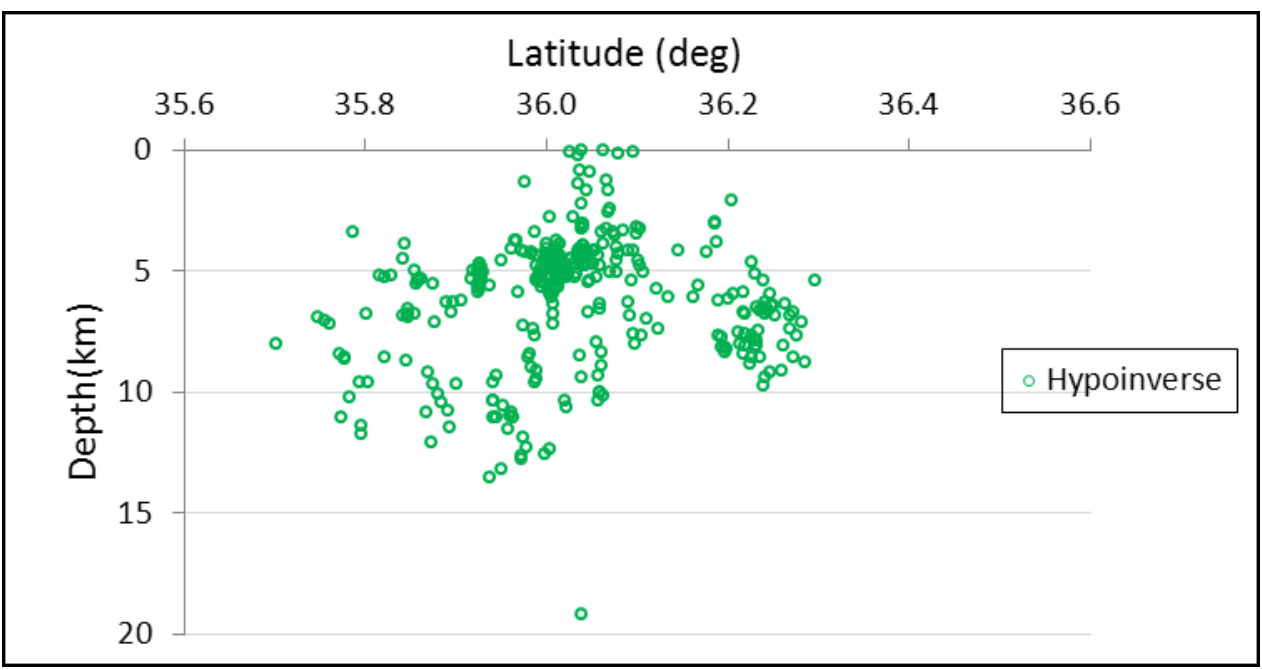

Figure 6(b) HYPOINVERSE latitude and depth distribution

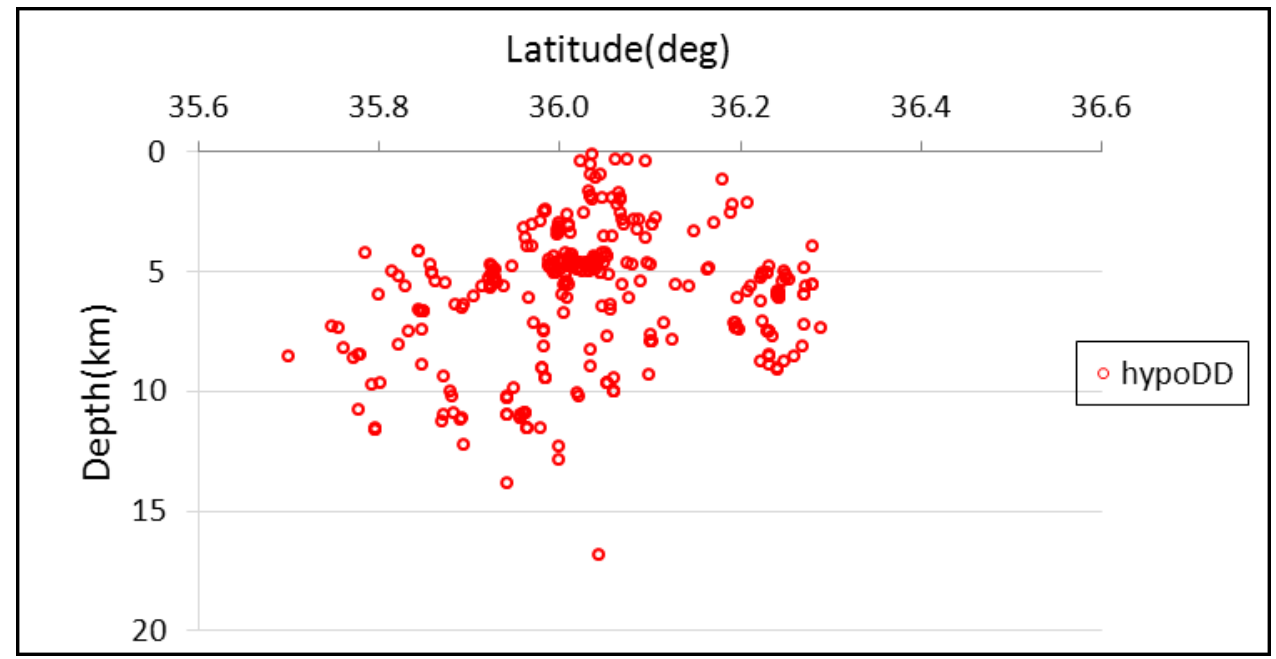

Figure 6(c) HypoDD latitude and depth distribution 

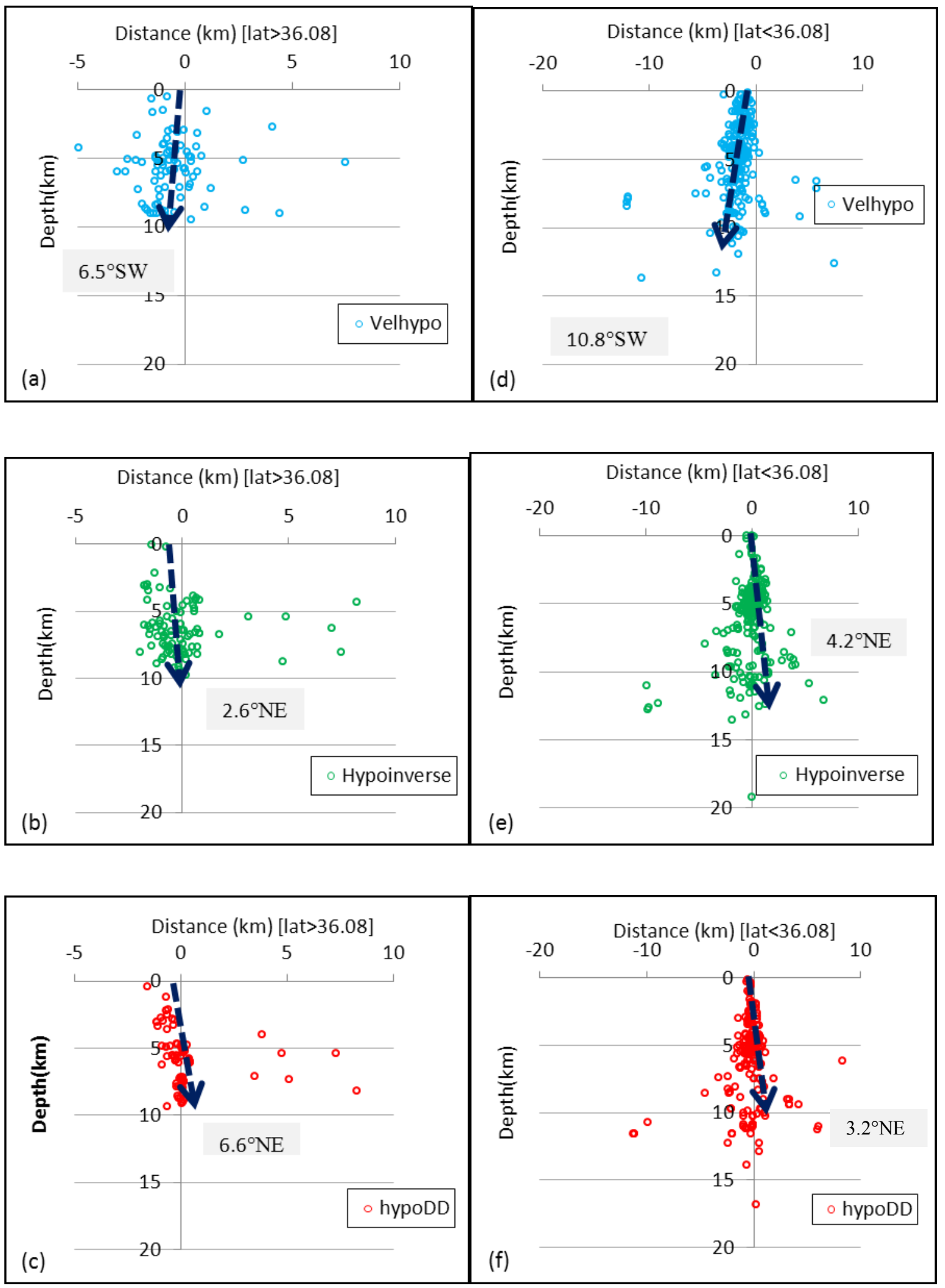

Figure 7 Focal depth distances from SAF showing dipping angles of SAF at latitude $>36.08^{\circ}$ and latitude $<36.08^{\circ}$ for Velhypo (a) \& (d), Hypoinverse (b) \& (e) and hypoDD (c) \& (f). 


\section{Acknowledgements:}

This work was funded by the Korean Meteorological Administration Research and Development Program under Grant CATER 2012-8130.

\section{References}

[1]. Afonso, Emido de V. L., Marcelo A., 2011. Genetic algorithm inversion of the average 1D crustal structure using local and regional earthquakes, Computers and Geosciences 37,1372-1380.

[2]. Aki, K. and Richards, P. G., 1980. Quantitative seismology theory and methods, W. H. Freeman, San Francisco.

[3]. Eberhart-Phillips, D., and A.J. Michael, 1993. Three-dimensional velocity structure, seismicity, and fault structure in the Parkfield region, central California, Journal of Geophysical Research 98, 1153-1172.

[4]. Fäh, D., Kind, F. and Giardini, D., 2001. A theoretical investigation of average H/V ratios, Geophys. J. Int., 145, 535-549.

[5]. Fuis, G.S., D.S.Scheirer, V.E.Langenheim, M.D.Kohler, 2012. A new perspective on the geometry of the San Andreas Fault in Southern California and its relationship to lithospheric structure, Bulletin of the Seismological Society of America,102, 236-251, dol 10.1785/0120110041.

[6]. Hahm, I.K., Kim, W. Lee, J.M., \& Jeon, J.S., 2007. Determination of hypocentral parameters of local earthquakes using weighting factor based on take-off angle, (MHYPO), Geosciences Journal,11, 39-49.

[7]. Klein, F.W., 1978. Hypocenter location program HYPOINVERSE, USGS Open File Report, $\quad 78-694$, 113pp, Menlo Park, CA.

[8]. Klein, F. W., 2002. User's guide to HYPOINVERSE-2000, a Fortran program o solve for earthquake locations and magnitudes, USGS Open FileReport,02-171,123pp, Menlo Park, CA.

[9]. Kim, W. \& Baag, C.-E., 2002. Rapid and accurate two-point ray tracing based on a quadratic equation of takeoff angle in layer media with constant or linearly varying velocity functions, Bulletin of the Seismological Society of America,92, 2251-2263.

[10]. Kim, W., Hahm, I.-K.,Ahn, S.J., \& Lim, D.H., 2006. Determining the hypocentral parameters for local earthquakes in 1-D using genetic algorithms. Geophysical Journal International, 166, 590-600.

[11]. Kim, W., Hahm, I.-K., Sheen, D.-H., \& Lim, D.H., 2008. Comparisons of accuracy and Stability tests among the methods determining hypocentral parameters: VELEST, HYPOSAT, hypoDD, and GA-MHYPO, S34A-08, American Geophysical Union, Fall meeting 2008, San Francisco, USA.

[12]. Kissling,E., Ellsworth, W.L., Eberhart-Phillips, D., \& Kradolfer, U., 1994. HYPOSAT Initial reference models in local earthquake tomography, Journal of Geophysical Research, 99, 19635-19646.

[13]. Lahr, J.C., 1980. HYPOELLIPSE/MULTICS: a computer program for determining local earthquake hypocentral parameters, magnitude, and first motion pattern. USGS Open FileReport,59-80,Denver.

[14]. Lee, W.H.K., \& Lahr, J.C., 1975. HYPO-71(revised): a computer program for determining local earthquake hypocenter, magnitude, and first motion pattern of local earthquakes, USGS Open File Report, 75-311,MenloPark, CA.

[15]. Li, Y.-G., W. L. Ellsworth, C. H. Thurber, P. E. Malin, and K. Aki, 1997. Fault-zone guided waves from explosions in the San Andreas fault at Parkfield and Cienega alley, California, Bulletin of the Seismological Society of America, 87,210-221.

[16]. Lomnitz, C., 2006. Three theorems of earthquake location, Bulletin of the Seismological Society of America, 96,306-312.

[17]. Michelini, A., and T. V. McEvilly, 1991. Seismological studies at Parkfield:I. simultaneous inversion for velocity structure and hypocenter susing B-splines parameterization, Bulletin of the Seismological Society of America, 81,524-552

[18]. Pavlis, G.L \& Booker, J.R., 1983.Progressive multiple events location (PHEL), Bulletin of the Seismological Society of America, 73, 1753-1777.

[19]. Schweitzer, J., 2001.HYPOSAT-an enhanced routine to locate seismic events, Pure and Applied Geophysics, 158, $277-289$.

[20]. Shearer,P. M.,2009.Introduction to Seismology, Cambridge University Press, New York.

[21]. Sieh, K. E., 1978. Slip along the San Andreas Fault associated with the great 1857 earthquake, Bulletin of the Seismological Society of America, 68, 1421-1448.

[22]. Thorne, Lay, and Terry, C.W., 1995. Modern Global Seismology, Academic Press, San Diego, California.

[23]. Thurber, C.H., 1985. Nonlinear earthquake location: Theory and Examples, Bulletin of the Seismological Society of America, 75, 779-790.

[24]. Thurber, C.H., 1992. Hypocenter-velocity structure coupling in local earthquake tomography, Physics of the Earth and Planetary Interiors, 75, 55-62.

[25]. Waldhauser, F., andW.L. Ellsworth, 2000. A double-difference earthquake Location algorithm: method and application to the Northern Hayward fault, California, Bulletin of the Seismological Society of America, 90, 1353-1368.

[26]. Waldhauser, F., W.L. Ellsworth, Schaff, D.P., and Cole, A., 2004. Streaks, multiplets, andholes: High-resolution spatio-temporal behavior of Parkfield seismicity, Geophysical Research Letters, 31, L18608, dol 10.1029/2004GL020649.

[27]. Walter, A.W. and Mooney, W. D., 1982. Crustal Structure of the Diablo and Gabilan ranges, Central California: a reinterpretation of existing data, Bulletin of the Seismological Society ofAmerica,72, 1567-1590. 
Appendix I: List of used stations and their corresponding calculated average delay.

\begin{tabular}{|c|c|c|c|c|c|c|c|c|c|c|c|}
\hline No. & Station & $\begin{array}{c}\text { Latitud } \\
\text { e (deg) }\end{array}$ & $\begin{array}{c}\text { Longitude } \\
\text { (deg) }\end{array}$ & $\begin{array}{l}\text { Elev } \\
(\mathbf{k m})\end{array}$ & $\begin{array}{c}\text { Delay } \\
\text { (sec) }\end{array}$ & No. & Station & $\begin{array}{c}\text { Latitude } \\
\text { (deg) }\end{array}$ & $\begin{array}{c}\text { Longitude } \\
\text { (deg) }\end{array}$ & $\begin{array}{l}\text { Elev } \\
(\mathbf{k m})\end{array}$ & $\begin{array}{c}\text { Delay } \\
\text { (sec) }\end{array}$ \\
\hline 1 & BAP & 36.1804 & -121.6444 & 1.193 & 0.0040 & 57 & PHS & 35.8238 & -121.0538 & 0.451 & 0.0699 \\
\hline 2 & BAV & 36.6460 & -121.0302 & 0.572 & 0.2700 & 58 & PHSB & 35.8240 & -121.0539 & 0.475 & -0.0171 \\
\hline 3 & BBG & 36.5780 & -121.0392 & 1.065 & 0.2214 & 59 & PIR & 35.5544 & -120.2233 & 0.471 & 0.0905 \\
\hline 4 & BBGB & 36.5785 & -121.0396 & 1.089 & 0.0680 & 60 & PJC & 36.0959 & -120.3716 & 0.403 & 0.2478 \\
\hline \begin{tabular}{|l}
5 \\
\end{tabular} & BCG & 36.7096 & -121.3428 & 0.250 & -0.1060 & 61 & PJU & 36.2270 & -120.5935 & 0.925 & 0.0752 \\
\hline 6 & BCW & 36.3065 & -121.5669 & 1.505 & -0.1783 & 62 & PKD & 35.9452 & -120.5416 & 0.583 & -0.0440 \\
\hline 7 & BEH & 36.6648 & -121.1754 & 0.334 & 0.6750 & 63 & PKL & 35.7730 & -120.3399 & 0.422 & 0.0289 \\
\hline 8 & BEM & 36.6611 & -121.0968 & 0.464 & -0.3880 & 64 & PKY & 35.2640 & -120.6667 & 0.101 & 0.1530 \\
\hline 9 & BJC & 36.5472 & -121.3939 & 0.173 & -0.0567 & 65 & PL11 & 35.9740 & -120.5512 & 0.627 & 0.1630 \\
\hline 10 & BJO & 36.6110 & -121.3142 & 1.021 & -0.4455 & 66 & PL11B & 35.9745 & -120.5516 & 0.659 & 0.0091 \\
\hline 11 & BMS & 36.6631 & -120.7929 & 0.780 & 0.5230 & 67 & PLO & 36.2463 & -121.0430 & 0.251 & -0.1178 \\
\hline 12 & BPC & 36.5734 & -121.6269 & 0.173 & 0.2995 & 68 & PMC & 35.7252 & -120.3706 & 0.471 & 0.0877 \\
\hline 13 & BPI & 36.4901 & -121.1696 & 0.301 & -0.1563 & 69 & PMG & 35.4298 & -120.5201 & 0.486 & -0.2305 \\
\hline 14 & $\mathrm{BPO}$ & 36.2284 & -121.7677 & 0.330 & -0.2450 & 70 & PMM & 35.9563 & .4985 & 0.751 & 0.1150 \\
\hline 15 & BPR & 36.4071 & -121.7306 & 0.711 & 0.0261 & 71 & PMP & 36.2157 & -120.7974 & 0.754 & -0.0864 \\
\hline 16 & BRM & 36.8451 & -120.8247 & 0.343 & -0.2390 & 72 & PMPB & 36.2159 & -120.8013 & 0.802 & -0.0197 \\
\hline 17 & BRV & 36.4247 & -121.0191 & 0.525 & 0.1380 & 73 & PMR & 35.7843 & -120.2368 & 0.498 & -0.0716 \\
\hline 18 & BSG & 36.4138 & -121.2552 & 0.161 & -0.1863 & 74 & PPC & 35.9497 & -120.5954 & 0.558 & -0.0922 \\
\hline 19 & BSM & 36.3837 & -121.4292 & 0.884 & -0.1465 & 75 & PPG & 35.8626 & -119.9565 & 0.177 & 0.4170 \\
\hline 20 & BSR & 36.6674 & -121.5203 & 0.375 & 0.0025 & 76 & PPO & 35.8667 & -120.6160 & 0.446 & 0.3045 \\
\hline 21 & BVL & 36.5749 & -121.1901 & 0.479 & -0.0560 & 77 & PPT & 36.1091 & -120.7242 & 0.481 & 0.0148 \\
\hline 22 & CCRB & 35.9572 & -120.5516 & 0.595 & -0.0393 & 78 & PSA & 36.0247 & -120.8892 & 0.150 & 0.0526 \\
\hline 23 & $\mathrm{CS}$ & 35.6005 & -121.0940 & 0.030 & 0.1480 & 79 & PSC & 35.5884 & -120.4279 & 0.326 & 0.0354 \\
\hline 24 & EADB & 35.8952 & & 0.469 & -0.0103 & 80 & PSM & 36.0688 & -120.5962 & 0.957 & 0.0297 \\
\hline 25 & FROB & 35.9110 & -120.4869 & 0.515 & -0.1444 & 81 & PSN & 35.7878 & -120.2951 & 0.390 & -0.0487 \\
\hline 26 & GHIB & 35.8322 & -120.3473 & 0.393 & -0.0698 & 82 & PSR & 35.8562 & -120.2804 & 0.480 & 0.0015 \\
\hline 27 & HAST & 36.3887 & -121.5514 & 0.542 & -0.0450 & 83 & PST & 35.9307 & -120.5148 & 0.559 & -0.0701 \\
\hline 28 & JCNB & 35.9390 & -120.4311 & 0.533 & 0.0798 & 84 & PTA & 35.3925 & -120.7078 & 0.802 & -0.1017 \\
\hline 29 & JCSB & 35.9212 & -120.4340 & 0.454 & 0.1352 & 85 & PTR & 35.6541 & -120.2133 & 0.594 & -0.1175 \\
\hline 30 & LCCB & 35.9800 & -120.5142 & 0.385 & 0.1342 & 86 & PVC & 35.9221 & -120.5350 & 0.770 & -0.0767 \\
\hline 31 & MMNB & 35.9565 & -120.4960 & 0.701 & 0.0615 & 87 & PWK & 35.8145 & -120.5119 & 0.470 & 0.1676 \\
\hline 32 & PAD & 35.6400 & -120.8662 & 0.430 & 0.0172 & 88 & PWM & 36.4327 & -120.2124 & 0.045 & -0.0490 \\
\hline 33 & PAG & 35.7325 & -120.2504 & 0.436 & -0.0310 & 89 & RAMR & 35.6360 & -120.8698 & 0.414 & 0.0150 \\
\hline 34 & PAGB & 35.7307 & -120.2499 & 0.480 & -0.0410 & 90 & RMNB & 36.0009 & -120.4777 & 1.164 & -0.0427 \\
\hline 35 & PAN & 35.7801 & -120.9071 & 0.426 & 0.0751 & 91 & SCC & 34.9409 & -120.1730 & 0.565 & 0.3080 \\
\hline 36 & PAP & 35.8958 & -121.3655 & 1.044 & -0.1866 & 92 & SCYB & 36.0094 & -120.5366 & 0.947 & -0.0329 \\
\hline 37 & PAR & 36.2493 & -120.3428 & 0.452 & 0.1360 & 93 & SIM & 35.3502 & -119.9965 & 0.578 & 0.0450 \\
\hline 38 & PBI & 35.1614 & -120.4750 & 0.522 & 0.1220 & 94 & SMNB & 35.9730 & -120.5799 & 0.698 & -0.0634 \\
\hline 39 & PBM & 35.3945 & -120.3539 & 1.049 & -0.2670 & 95 & VARB & 35.9261 & -120.4471 & 0.475 & 0.1005 \\
\hline 40 & PBP & 35.5791 & -120.0775 & 0.569 & 0.2178 & 96 & VCAB & 35.9216 & -120.5339 & 0.755 & -0.1621 \\
\hline 41 & PBS & 35.7457 & -120.1490 & 0.811 & -0.0855 & 97 & YEG & 35.4366 & -119.9601 & 0.907 & 0.0418 \\
\hline
\end{tabular}


Appendix II Comparison of VELHYPO relocated events with results of HypoDD and HYPOINVERSE.

\begin{tabular}{|c|c|c|c|c|c|c|c|c|c|c|c|c|c|c|c|c|}
\hline \multirow[b]{2}{*}{$\mathrm{S} / \mathrm{N}$} & \multirow[b]{2}{*}{ Event ID } & \multirow[b]{2}{*}{ Mag } & \multirow[b]{2}{*}{$\begin{array}{c}\text { Date } \\
\text { (yy/mm/dd) }\end{array}$} & & & & poDD & & & HYPO & INVERSE & & & & LHYPO & \\
\hline & & & & hh:mm & \begin{tabular}{|l}
$\begin{array}{l}\text { Time } \\
\text { (ss) }\end{array}$ \\
\end{tabular} & $\begin{array}{c}\text { Lat } \\
\text { (deg) }\end{array}$ & $\begin{array}{l}\begin{array}{l}\text { Long } \\
\text { (deg) }\end{array} \\
\end{array}$ & \begin{tabular}{|l} 
Dept \\
$(\mathrm{km})$
\end{tabular} & \begin{tabular}{|l}
$\begin{array}{l}\text { Time } \\
\text { (ss) }\end{array}$ \\
\end{tabular} & $\begin{array}{c}\begin{array}{c}\text { Lat } \\
(\mathrm{deg})\end{array} \\
\end{array}$ & $\begin{array}{l}\begin{array}{l}\text { Long } \\
\text { (deg) }\end{array} \\
\end{array}$ & $\begin{array}{l}\text { Dept } \\
(\mathrm{km})\end{array}$ & \begin{tabular}{|l} 
Time \\
(ss)
\end{tabular} & $\begin{array}{c}\begin{array}{c}\text { Lat } \\
\text { (deg) }\end{array} \\
\end{array}$ & $\begin{array}{l}\begin{array}{l}\text { Long } \\
(\mathrm{deg})\end{array} \\
\end{array}$ & $\begin{array}{l}\text { Dept } \\
(\mathrm{km})\end{array}$ \\
\hline 1 & 21075061 & 1.19 & $2000 / 01 / 01$ & $5: 19$ & 4.10 & 36.0349 & -120.5807 & 9.00 & 24.02 & 36.0390 & -120.5773 & 9.37 & 23.57 & 36.0109 & 120.6081 & 9.00 \\
\hline 2 & 21075067 & 1.14 & $2000 / 01 / 01$ & $6: 50$ & 7.03 & 35.9911 & -120.5495 & 4.69 & 57.08 & 35.9897 & -120.5488 & 4.76 & 56.60 & 35.9819 & -120.5663 & 4.72 \\
\hline 3 & 21075241 & 1.25 & $2000 / 01 / 02$ & $10: 57$ & 3.36 & 36.2121 & -120.7763 & 5.64 & 33.44 & 36.2063 & -120.7857 & 5.98 & 32.72 & 36.2002 & -120.7795 & 5.92 \\
\hline 4 & 21075546 & 0.00 & $2000 / 01 / 03$ & $17: 41$ & 6.00 & 35.9568 & -120.5066 & 11.10 & 15.75 & 35.9503 & -120.5055 & 13.17 & 14.90 & 35.9338 & -120.5329 & 13.28 \\
\hline 5 & 21076108 & 1.58 & $2000 / 01 / 07$ & 9:59 & 3.79 & 36.1896 & -120.7617 & 2.54 & 53.91 & 36.1858 & -120.7720 & 2.97 & 53.53 & & -120.7701 & 0.67 \\
\hline 6 & 21076261 & 1.12 & $2000 / 01 / 08$ & $5: 31$ & 7.92 & 35.9891 & -120.5483 & 4.50 & 27.94 & 35.9890 & -120.5455 & 4.39 & 27.85 & 35.9793 & -120.5578 & 2.74 \\
\hline 7 & \begin{tabular}{|l|}
21076477 \\
\end{tabular} & 1.97 & $2000 / 0$ & $23: 18$ & 0.75 & 36.2795 & \begin{tabular}{|l|}
120.8540 \\
\end{tabular} & 5.58 & 50.66 & 36.2812 & -120.8505 & 7.14 & 50.69 & 36.2753 & -120.8586 & 5.57 \\
\hline 8 & 21077337 & 1.40 & $2000 / 01 / 13$ & $13: 00$ & 0.79 & 36.2404 & -120.8058 & 9.09 & 20.84 & 36.2403 & -120.8080 & 9.37 & 20.99 & 36.2348 & -120.8184 & 7.28 \\
\hline 9 & 21077513 & 1.20 & $2000 / 01 / 14$ & $13: 23$ & 2.46 & 35.8226 & -120.3723 & 8.10 & 52.44 & 35.8215 & -120.3717 & 8.57 & 52.40 & 35.8224 & -120.3741 & 7.54 \\
\hline 10 & 21077661 & 2.26 & & $10: 29$ & 2.81 & 35.9892 & -120.5472 & 4.74 & 32.77 & 35.9883 & & 5.40 & 32.70 & 35.9811 & -120.5593 & 3.06 \\
\hline 11 & 2107 & 1.30 & 200 & $10: 34$ & 8.64 & 35.9895 & -120.5476 & 4.82 & 18.60 & 35.9923 & -120.5455 & 5.17 & 18.46 & 35.98 & -120.5601 & 2.47 \\
\hline 12 & 21077835 & 1.35 & $2000 / 0$ & $3: 11$ & 8.18 & 36.0353 & -120.6000 & 1.88 & 38.15 & 36.0395 & -120.5977 & 3.04 & 37.57 & 36.0287 & -120.6083 & 0.28 \\
\hline 13 & 21078052 & 1.26 & $2000 / 01 / 17$ & $13: 50$ & 8.20 & 36.0350 & -120.5999 & 1.85 & 58.25 & 36.0398 & .5940 & 3.08 & 57.90 & 36.0280 & -120.6006 & 0.63 \\
\hline 14 & 21078108 & 1.68 & $2000 / 01 / 17$ & 19:29 & 1.79 & 35.9841 & -120.4840 & 9.43 & 51.74 & 35.9862 & -120.4802 & 9.60 & $\$ 1.79$ & 35.9700 & -120.5100 & 8.26 \\
\hline 15 & 21078120 & 1.46 & $2000 / 01 / 17$ & $20: 70$ & 1.20 & 36.0359 & -120.5912 & 4.83 & 1.20 & 36.0367 & 893 & 4.61 & 0.62 & 36.0204 & 151 & 4.42 \\
\hline 16 & 2107 & 1.02 & 200 & $20: 31$ & 8.80 & 36.0357 & -12 & 4.86 & 18.80 & & & 4.28 & 18.36 & & 909 & 4.13 \\
\hline 17 & 210 & 1.29 & 17 & $22: 10$ & 6.65 & 35.9844 & -120 & 9.44 & 16.54 & 35.9890 & 820 & 9.15 & 16.43 & 35.9 & 082 & 8.99 \\
\hline 18 & 2107 & 1.48 & 17 & $23: 30$ & 5.79 & 35.9845 & 343 & 9.44 & 15.79 & 35.9885 & 773 & 9.48 & 15.72 & 35.9 & 082 & 8.78 \\
\hline 19 & 30221651 & 1.64 & $2000 / 01 / 18$ & $6: 19$ & 6.05 & 35.8596 & -120 & 5.06 & 16.11 & 35.8580 & 035 & 5.35 & 15.79 & 35.8 & 097 & 5.03 \\
\hline 20 & 21078210 & 2.24 & $2000 / 01 / 18$ & $6: 50$ & 7.23 & 35.8596 & -120.4028 & 5.08 & 57.24 & 35.8573 & 037 & 5.42 & 57.04 & 35.8 : & 137 & 4.54 \\
\hline 21 & 210 & 1.42 & & $11: 36$ & 9.46 & 36.0972 & -12 & 4.68 & 9.45 & 28 & & 4.81 & 9.16 & & & 4.99 \\
\hline 22 & 210 & 2.02 & & $14: 18$ & 9.30 & 36.0473 & -12 & 6.44 & \begin{tabular}{|l|}
.15 \\
9.23
\end{tabular} & & & 6.73 & 9.14 & 36.0 & & 3.93 \\
\hline 23 & 2107 & 2.02 & 20 & $17: 80$ & 2.66 & 36.1284 & -12 & 5.56 & 52.72 & 36.1212 & 50 & 5.73 & 52.42 & 36.1 & 31 & 5.96 \\
\hline 24 & 2107 & 2.31 & 20 & $3: 20$ & 3.90 & 35.8589 & -120 & 5.08 & 13.93 & 35.8568 & 25 & 5.51 & 13.50 & 35.8 & 088 & 5.74 \\
\hline 25 & 2107 & 1.03 & 200 & $17: 60$ & 2.12 & 36.0409 & -120. & 4.96 & 12.11 & 36.0432 & 918 & 4.24 & 12.21 & 36.0 & 146 & 4.37 \\
\hline 26 & 2107 & 1.19 & 200 & $19: 36$ & 0.41 & 35.9818 & -120 & 9.01 & 0.39 & 35.9832 & 93 & 8.99 & 0.18 & 35.9 & 090 & 8.39 \\
\hline 27 & 210 & 1.18 & & $5: 44$ & 3.32 & 35.9882 & -12 & 4.76 & 23.36 & \begin{tabular}{|l|}
55.9887 \\
\end{tabular} & & 5.33 & 23.01 & 35. & 664 & 2.37 \\
\hline 28 & 210 & 0.97 & & $10: 30$ & 8.19 & 36.0755 & 87 & 4.68 & 38.19 & 773 & 58 & 4.60 & 37.88 & $\beta 6.0$ & 746 & 5.59 \\
\hline 29 & 2107 & 1.62 & 20 & $3: 60$ & 5.32 & 36.2085 & -12 & 2.16 & 35.28 & 035 & 362 & 2.12 & 35.44 & 36.2 & 866 & 1.70 \\
\hline 30 & 2107 & 1.05 & 20 & $23: 30$ & 7.81 & 35.7720 & -120 & 8.60 & 17.77 & 35.7707 & 215 & 8.45 & 17.59 & 35.7727 & 188 & 9.00 \\
\hline 31 & 21080120 & 1.96 & 20 & $17: 13$ & 4.96 & 35.9997 & -120 & 4.58 & 24.91 & 36.0007 & 565 & 5.17 & 24.77 & 35.9 & 681 & 2.46 \\
\hline 32 & 2108 & 1.15 & & $3: 20$ & 8.69 & 36.0043 & -12 & 4.55 & 8.80 & & & 4.52 & 8.28 & 35.9 & & 4.25 \\
\hline \begin{tabular}{|l|}
33 \\
\end{tabular} & & 1.10 & & $4: 20$ & \begin{tabular}{|l|}
0.85 \\
\end{tabular} & 35.8 & & 5.52 & 33.00 & & & 5.53 & 32.91 & 35.8 & $\frac{05}{28}$ & 4.82 \\
\hline 34 & 302 & 1.24 & & $6: 48$ & 6.76 & 35.9994 & & 4.56 & 6.73 & & & 4.92 & 6.56 & 35.9 & 553 & 2.40 \\
\hline 35 & \begin{tabular}{|l}
2108 \\
\end{tabular} & 1.16 & \begin{tabular}{|l}
20 \\
\end{tabular} & $13: 13$ & 4.49 & 35.7562 & -120 & 7.40 & 14.60 & 545 & 87 & 7.03 & 14.74 & 35.7 & 183 & 5.82 \\
\hline 36 & 2108 & 1.27 & 20 & $14: 50$ & 7.93 & 36.1151 & -120.6 & 7.14 & 17.96 & 102 & 303 & 7.00 & 17.04 & 36.1 & 835 & 8.99 \\
\hline 37 & 21080723 & 1.41 & 200 & $5: 56$ & 8.07 & 36.0449 & -120. & 0.99 & 58.13 & 36.0475 & 112 & 0.90 & 57.97 & 36.0 & 341 & 3.88 \\
\hline 38 & \begin{tabular}{|l|}
21080765 \\
\end{tabular} & 1.18 & & $12: 15$ & 0.73 & 35.9816 & & 9.02 & 0.98 & & & 8.60 & 1.03 & & & 7.93 \\
\hline 39 & 210 & 2.00 & & $1: 39$ & 1.76 & 36.0 & & 0.99 & 31.76 & & & 0.85 & 31.51 & & & 4.17 \\
\hline 40 & 210 & 1.27 & & $11: 50$ & 5.59 & 36.2326 & 59 & 7.50 & 25.60 & 15 & 67 & 7.91 & 25.48 & 36.2 & 53 & 6.92 \\
\hline 41 & 3050 & 1.56 & 200 & 13:56 & 4.86 & 36.0752 & -120 & 0.32 & 54.90 & 795 & 465 & 0.18 & 54.97 & 36.0 & 682 & 0.25 \\
\hline 42 & 21082548 & 1.28 & 111 & $14: 59$ & 6.35 & 36.0769 & -120 & 6.14 & 16.33 & 782 & 142 & 4.33 & 15.62 & 36.0 & 358 & 6.58 \\
\hline 43 & 21083244 & 2.14 & $2000 / 02 / 17$ & $8: 52$ & 9.84 & 36.0907 & -120 & 5.42 & 29.89 & 898 & 40 & 6.27 & 29.83 & 36.0 & 784 & 6.54 \\
\hline 44 & 21084133 & 1.18 & & $10: 45$ & 9.94 & 35.7005 & & 8.56 & 9.98 & & & 7.99 & 9.83 & & 718 & 7.50 \\
\hline 45 & 210 & 1.08 & & $18: 44$ & 8.58 & 35.8923 & -12 & 6.55 & 58.55 & & & 6.73 & 58.63 & 35.8 & 46 & 5.28 \\
\hline 46 & 3022 & 1.11 & 200 & $5: 29$ & 8.54 & 36.0336 & -120 & 1.63 & 8.46 & 36.0353 & 958 & 1.40 & 8.15 & 36.0 & 952 & 0.62 \\
\hline 47 & 21084953 & 1.20 & 20 & $4: 60$ & 1.00 & 35.9988 & -120.5441 & 12.88 & 1.07 & 9975 & 413 & 12.56 & 0.99 & 35.9 & 600 & 10.62 \\
\hline 48 & 21085649 & 1.94 & $/ 03 / 07$ & 19:50 & 6.68 & 36.1800 & -120.7524 & 1.19 & 6.84 & 36.1885 & 433 & 3.83 & 6.65 & 36.1 & 380 & 1.59 \\
\hline 49 & 21086092 & 1.41 & & $3: 59$ & 1.95 & 36.2306 & & 5.09 & 11.95 & & & 8.19 & 12.07 & & & 3.04 \\
\hline 50 & 210 & 1.72 & & $23: 14$ & 0.40 & 35.9 & & 5.66 & 10.39 & & & 5.71 & 10.20 & & & 4.62 \\
\hline 51 & 210 & 1.14 & & $23: 17$ & 5.60 & 35.9243 & & 5.69 & 5.56 & & & 5.57 & 5.49 & 35.9 & & 4.98 \\
\hline 52 & \begin{tabular}{|l|}
21086417 \\
\end{tabular} & 1.07 & $/ 12$ & $23: 40$ & 9.80 & 35.9243 & -120.4715 & 5.65 & \begin{tabular}{|l|}
9.82 \\
\end{tabular} & 35.9242 & 730 & 5.51 & 9.18 & 35.9218 & 846 & 6.23 \\
\hline 53 & 21086460 & 1.24 & $3 / 13$ & $8: 57$ & 5.04 & 36.0537 & -120.6064 & 9.69 & 54.92 & 36.0582 & -120.5987 & 10.00 & 55.07 & 36.0378 & 196 & 7.24 \\
\hline 54 & 21086462 & 1.36 & $3 / 13$ & $9: 10$ & 0.60 & 36.0536 & -120. & 9.70 & 10.54 & & 007 & 10.01 & 10.66 & 36.0 & 192 & 7.40 \\
\hline 55 & 2108 & 1.14 & & $10: 46$ & 6.00 & 36.0530 & & 9.69 & 5.98 & & & 9.35 & 5.89 & & & 7.85 \\
\hline 56 & 2108 & 1.42 & & $8: 30$ & 7.45 & 36.1652 & & 4.83 & 27.45 & & & 5.61 & 27.23 & & & 4.91 \\
\hline 57 & \begin{tabular}{|l|}
21086598 \\
\end{tabular} & 1.28 & 200 & $17: 34$ & 8.95 & 35.8631 & -120.4068 & 5.41 & 8.95 & 35.8623 & -120.4068 & 5.36 & 8.80 & 35.8674 & -120.4107 & 4.71 \\
\hline 58 & 21086642 & 2.29 & $/ 03 / 14$ & $23: 34$ & 7.91 & 35.9246 & -120.4721 & 5.58 & 37.82 & 35.9238 & -120.4717 & 5.90 & 37.88 & 35.9184 & -120.4810 & 3.16 \\
\hline \begin{tabular}{l|l}
59 \\
\end{tabular} & 21087210 & 1.42 & $/ 03 / 18$ & $11: 00$ & 2.41 & 36.2311 & -120.7942 & 7.51 & 2.41 & 36.2313 & -120.7952 & 8.06 & 2.36 & 36.2314 & 120.7942 & 7.12 \\
\hline 60 & 21088017 & 1.53 & 200 & $14: 45$ & 0.54 & 35.9905 & -120.5485 & 4.73 & 10.59 & 35.9913 & -120.5473 & 5.31 & 10.38 & 35.9 & 643 & 4.00 \\
\hline 61 & 2108 & 1.40 & & $16: 50$ & 1.73 & 36.0202 & & 4.96 & 1.66 & & & 5.23 & 1.42 & & & 4.40 \\
\hline $\begin{array}{l}01 \\
62\end{array}$ & \begin{tabular}{|l|}
21088567 \\
\end{tabular} & 1.29 & 200 & $0: 56$ & \begin{tabular}{|l|}
7.61 \\
\end{tabular} & 36.0687 & -120.6302 & 2.59 & 17.56 & & -120.6220 & 3.51 & $\frac{1.42}{17.22}$ & 36.0490 & 510 & 3.14 \\
\hline 63 & \begin{tabular}{|l|}
21089675 \\
\end{tabular} & 0.85 & $2000 / 04 / 02$ & $3: 30$ & 7.23 & 35.8477 & -120.3952 & 8.89 & 17.27 & 35.8455 & -120.3952 & 8.68 & 17.36 & 35.8490 & -120.3997 & 7.24 \\
\hline 64 & 21090082 & 0.00 & $2000 / 04 / 04$ & 4: 90 & 5.21 & 35.9667 & -120.5235 & 6.12 & 25.24 & 35.9680 & -120.5217 & 5.87 & 25.17 & 35.9606 & -120.5391 & 3.31 \\
\hline 65 & 30221696 & 0.96 & $2000 / 04 / 07$ & 21:29 & 2.21 & 35.9258 & -120.4723 & 4.78 & 22.22 & 35.9262 & -120.4710 & 4.70 & 2.08 & 35.9174 & 880 & 3.58 \\
\hline 66 & 21091100 & 2.89 & $2000 / 04 / 08$ & $6: 51$ & 2.31 & 35.8006 & -120.3480 & 6.00 & 12.25 & 35.8003 & -120.3472 & 6.79 & 11.94 & 35.7 & -120.3575 & 6.64 \\
\hline 67 & 21091223 & 2.00 & 200 & $3: 59$ & \begin{tabular}{|l|}
2.51 \\
9.54
\end{tabular} & 36.1976 & -120.7599 & 7.39 & 19.58 & 36.1930 & -120.7637 & 8.19 & 19.48 & 36.1878 & 120.7713 & 6.65 \\
\hline 68 & 21091336 & 1.57 & $2000 / 04 / 09$ & $23: 27$ & 1.62 & 36.0948 & -120.6752 & 0.42 & 51.66 & 36.0958 & -120.6742 & 0.09 & 51.55 & 36.0930 & -120.6652 & 5.03 \\
\hline 69 & 21091487 & 0.94 & $2000 / 04 / 10$ & $19: 52$ & 9.15 & 36.0586 & -120.6154 & 3.55 & 19.16 & 36.0607 & -120.6113 & 3.38 & 18.70 & 36.0504 & -120.6166 & 2.37 \\
\hline 70 & 21092235 & 2.82 & $2000 / 04 / 15$ & 13:06 & 6.28 & 36.1984 & -120.7607 & 7.44 & 56.24 & 36.1965 & -120.7633 & 8.36 & 56.10 & 36.1881 & -120.7708 & 8.44 \\
\hline 71 & 21092364 & 1.16 & $2000 / 04 / 16$ & $8: 57$ & 5.95 & 36.0393 & -120.5944 & 4.61 & 35.93 & 36.0420 & -120.5878 & 4.18 & 35.75 & 36.0325 & -120.5995 & 2.50 \\
\hline 72 & 21092841 & 0.94 & $2000 / 04 / 19$ & $18: 28$ & 5.60 & 36.0507 & -120.6056 & 4.24 & 15.58 & 36.0527 & -120.6015 & 4.16 & 14.90 & 36.0452 & -120.6025 & 4.51 \\
\hline
\end{tabular}


Appendix II Comparison of VELHYPO relocated events with results of HypoDD and HYPOINVERSE.

\begin{tabular}{|c|c|c|c|c|c|c|c|c|c|c|c|c|c|c|c|c|}
\hline & & & & & & & poDD & & & HYPO & INVERSE & & & & YPO & \\
\hline $\mathrm{S} / \mathrm{N}$ & Event ID & Mag & $\begin{array}{c}\text { Date } \\
\text { (yy } / \mathrm{mm} / \mathrm{dd})\end{array}$ & hh:mm & \begin{tabular}{|l} 
Time \\
(ss)
\end{tabular} & $\begin{array}{c}\text { Lat } \\
\text { (deg) }\end{array}$ & $\begin{array}{l}\begin{array}{l}\text { Long } \\
\text { (deg) }\end{array} \\
\end{array}$ & $\begin{array}{l}\text { Dept } \\
(\mathrm{km})\end{array}$ & $\begin{array}{l}\text { Time } \\
\text { (ss) }\end{array}$ & $\begin{array}{c}\text { Lat } \\
\text { (deg) }\end{array}$ & $\begin{array}{l}\begin{array}{l}\text { Long } \\
\text { (deg) }\end{array} \\
\end{array}$ & $\begin{array}{l}\text { Dept } \\
(\mathrm{km})\end{array}$ & \begin{tabular}{|l}
$\begin{array}{l}\text { Time } \\
\text { (ss) }\end{array}$ \\
\end{tabular} & $\begin{array}{c}\text { Lat } \\
\text { (deg) }\end{array}$ & $\begin{array}{l}\begin{array}{l}\text { Long } \\
\text { (deg) }\end{array} \\
\end{array}$ & $\begin{array}{l}\text { Dept } \\
(\mathrm{km})\end{array}$ \\
\hline 73 & 21092877 & 1.63 & $2000 / 04 / 19$ & $23: 36$ & 8.79 & 35.9306 & -120.4791 & 5.46 & 38.76 & 35.9288 & -120.4793 & 5.34 & 38.44 & 35.9212 & -120.4960 & 4.48 \\
\hline 74 & 21093272 & 1.17 & $2000 / 04 / 22$ & $9: 51$ & 4.50 & 35.7486 & -120.2962 & 7.32 & 4.50 & 35.7475 & -120.2935 & 6.95 & 4.66 & 35.7467 & -120.2919 & 5.71 \\
\hline 75 & 21093319 & 0.95 & $2000 / 04 / 22$ & $17: 31$ & 5.08 & 35.9977 & -120.5596 & 3.45 & 15.04 & 35.9973 & -120.5603 & 4.91 & 4.74 & 35.9854 & -120.5753 & 4.84 \\
\hline 76 & 21093986 & 1.16 & $2000 / 04 / 26$ & 19:28 & 7.18 & 36.0218 & -120.5633 & 0.23 & 7.04 & 36.0228 & -120.5628 & 10.65 & 7.12 & 36.0063 & -120.5814 & 8.40 \\
\hline 77 & 21094494 & 2.87 & $2000 / 04 / 29$ & 17:50 & 1.05 & 35.7929 & -120.3438 & 9.72 & 11.07 & 35.7937 & -120.3452 & 9.64 & 10.40 & 35.7832 & -120.3656 & 10.45 \\
\hline 78 & 21094985 & 1.45 & $2000 / 05 / 02$ & 19:14 & 1.18 & 36.0528 & -120.6073 & 4.35 & 11.13 & 36.0580 & -120.6005 & 4.79 & 40.98 & 36.0460 & -120.6167 & 2.71 \\
\hline 79 & 30221801 & 1.21 & $2000 / 05 / 03$ & $4: 46$ & 8.09 & 36.0378 & -120.5926 & 4.78 & 8.05 & 36.0407 & -120.5880 & 4.75 & 7.86 & 36.0269 & -120.6079 & 0.64 \\
\hline 80 & 21096053 & 2.77 & $2000 / 05 / 07$ & $15: 50$ & 2.48 & 36.2504 & -120.8144 & 5.16 & 32.48 & 36.2488 & -120.8157 & 6.43 & $\beta 2.49$ & 36.2468 & -120.8230 & 4.14 \\
\hline 81 & 2109 & 3.10 & $2000 / 0$ & 16:50 & 0.68 & 36.2547 & -120.8192 & 5.34 & 10.49 & 36.2502 & -120 & 6.42 & 0.59 & 36.2513 & -120.8229 & 3.12 \\
\hline 82 & 2109 & 1.27 & $2000 / 0$ & $1: 47$ & 5.56 & 36.2313 & -120.7967 & 4.82 & 15.62 & 36.2272 & -120 & 4.64 & 45.68 & 36.2303 & 0.8038 & 2.90 \\
\hline 83 & 21096133 & 1.41 & $2000 / 05 / 08$ & $8: 40$ & 4.61 & 36.0377 & -120.5925 & 4.72 & 44.59 & 36.0400 & -120.5898 & 4.79 & 44.38 & 36.0220 & -120.6175 & 4.41 \\
\hline 84 & 30221823 & 1.05 & $2000 / 05 / 09$ & $7: 14$ & 4.90 & 35.9235 & -120.4794 & 4.75 & 54.80 & 35.9267 & -120.4765 & 4.73 & 54.63 & 35.9181 & .4944 & 4.41 \\
\hline 85 & 21096586 & 1.14 & $2000 / 05 / 10$ & $1: 36$ & 3.15 & 35.9644 & -120.6847 & 1.55 & 23.00 & 35.9730 & 718 & 12.65 & 23.10 & 35.9565 & 6876 & 7.77 \\
\hline 86 & 210 & 1.23 & 10 & $8: 10$ & 4.80 & 35.9645 & -120 & 1.55 & 24.59 & 35.9727 & 22 & 2.80 & 24.66 & 35.9576 & 381 & 7.88 \\
\hline 87 & 210 & 0.00 & 10 & $8: 48$ & 8.06 & 35.9647 & -120 & 11.55 & 7.97 & 35.9782 & 42 & 12.32 & 7.87 & 35.9576 & 395 & 8.11 \\
\hline 88 & 2109 & 1.35 & $2000 / 0$ & $23: 33$ & 1.79 & 36.2236 & -120.7874 & 5.29 & 31.91 & 36.2118 & -120 & 7.57 & \$1.69 & 36.2172 & -120.7950 & 8.90 \\
\hline 89 & 21096834 & 2.11 & $2000 / 0$ & $6: 45$ & 9.94 & 36.2245 & -120.7871 & 5.16 & 40.00 & 36.2190 & -120 & 8.11 & 40.00 & 36.2185 & -120.7982 & 1.52 \\
\hline 90 & 2109 & 1.40 & 12 & $12: 41$ & 8.18 & 36.1940 & -120 & 7.17 & 18.10 & 36.11 & & 8.20 & 17.78 & 36.2015 & 7516 & 8.59 \\
\hline 91 & 210 & 1.11 & 12 & $13: 22$ & 4.01 & 35.9833 & -120 & 8.12 & 4.00 & 35.9812 & 03 & 8.46 & 3.81 & 35.9700 & 386 & 7.15 \\
\hline 92 & 210 & 1.33 & 13 & $11: 43$ & 6.33 & 35.9996 & -12 & 3.25 & 36.36 & 36.0002 & 07 & 4.40 & 36.09 & 35.9926 & 31 & 2.40 \\
\hline 93 & 302 & 0.00 & 13 & $22: 00$ & 7.31 & 36.0603 & -120 & 10.04 & 37.43 & 36.0615 & 80 & 8.93 & 37.10 & 35.9778 & 38 & 8.42 \\
\hline 94 & 2109 & 1.84 & 14 & $17: 27$ & 8.39 & 35.9982 & -120.5 & 3.25 & 58.42 & 35.9985 & -12 & 4.44 & 58.15 & 35.9902 & 705 & 2.50 \\
\hline 95 & 2109 & 1.10 & 15 & $1: 40$ & 5.70 & 35.7860 & -120 & 4.27 & 15.72 & 35.7858 & -12 & 3.40 & 15.61 & 35.7863 & 252 & 1.98 \\
\hline 96 & $210^{5}$ & 1.12 & 16 & $8: 90$ & 6.95 & 35.9932 & -120 & 5.10 & 6.94 & 35.9962 & -12 & 5.49 & 6.49 & 35.9864 & 998 & 4.91 \\
\hline 97 & 210 & 0.92 & 17 & $16: 47$ & 3.57 & 35.9627 & -12 & 3.61 & 43.58 & 35.9 & & 3.77 & 43.54 & 35.9 & 23 & 2.78 \\
\hline 98 & 210 & 1.75 & 20 & $20: 38$ & 6.45 & 36.1717 & -12 & 2.99 & 16.44 & 36.1768 & & 4.26 & 16.19 & 36.1 & 320 & 3.16 \\
\hline 99 & 2109 & 1.33 & 20 & $22: 56$ & 8.57 & 36.0132 & -120.5 & 3.41 & 28.71 & 36.0152 & -120 & 3.86 & 8.08 & 36.0077 & 858 & 4.97 \\
\hline 100 & 2109 & 1.55 & 21 & $5: 43$ & 1.26 & 36.0210 & -120 & 4.66 & 11.23 & 36.0228 & & 5.06 & 10.94 & 36.0139 & 916 & 4.23 \\
\hline 101 & $210^{c}$ & 1.70 & 21 & $9: 80$ & 7.55 & 36.0830 & -12 & 2.87 & 57.53 & 36.0 & & 4.14 & $\$ 7.15$ & 36.0 & & 4.01 \\
\hline 102 & 210 & 2.77 & 22 & $20: 10$ & 3.38 & 36.0139 & -120 & 4.31 & 13.33 & 36.0 & -12 & 5.17 & 3.21 & 36.0 & 28 & 2.50 \\
\hline 103 & 210 & 2.31 & & $20: 13$ & 9.35 & 36.0132 & -12 & 4.31 & 9.43 & 36 & & 5.08 & 9.27 & 36.0 & & 2.51 \\
\hline 104 & $210^{c}$ & 1.26 & 24 & $1: 38$ & 7.96 & 35.9260 & 34 & 5.17 & 18.05 & 35.9 & & 5.04 & 7.63 & 35.9 & 73 & 5.24 \\
\hline 105 & 21099834 & 1.05 & $/ 24$ & $2: 00$ & 4.73 & 35.9260 & -120 & 5.15 & 34.62 & 35.9272 & -12 & 5.26 & 34.29 & 35.9207 & 394 & 5.28 \\
\hline 106 & 2109 & 1.10 & 24 & $8: 26$ & 7.87 & 35.9259 & -12 & 5.16 & 57.89 & 35.9267 & -12 & 4.73 & $\$ 7.39$ & 35. & 355 & 4.98 \\
\hline 107 & 2110 & 1.42 & 25 & $9: 26$ & 3.07 & 36.0113 & -120 & 4.55 & 43.05 & 36.0 & -12 & 4.98 & 12.80 & 36.0 & 313 & 4.06 \\
\hline 108 & 302 & 10 & & $9: 27$ & 4.16 & 36.0116 & & 4.54 & 34.17 & 36 & & 4.43 & $\beta 3.58$ & 36. & & 4.93 \\
\hline 109 & 211 & 1.55 & 27 & $12: 28$ & 1.05 & 36.0439 & -12 & 6.82 & 51.13 & 36.0 & & 19.19 & 52.67 & 35.9 & 39 & 0.99 \\
\hline 110 & 211 & 1.44 & 28 & $3: 51$ & 8.24 & 36.0704 & -120 & 5.55 & 58.14 & & & 5.09 & $\$ 7.67$ & 36.0 & 379 & 6.41 \\
\hline 111 & 2110 & 0.78 & 28 & $14: 37$ & 3.56 & 35.8154 & -120 & 4.98 & 23.57 & 35.8153 & -12 & 5.18 & 3.16 & 35.8178 & 595 & 5.14 \\
\hline 112 & 2110 & 1.11 & 29 & $16: 10$ & 5.24 & 36.0206 & -120 & 4.89 & 25.27 & 36.0 & & 4.76 & 24.96 & 36.0122 & 871 & 4.18 \\
\hline 113 & 211 & 0.85 & & $6: 10$ & 4.20 & 35.7616 & & 8.24 & 34.27 & 35.7 & & 7.19 & 34.07 & 35.7 & 28 & 7.14 \\
\hline 114 & 211 & 1.39 & 09 & $6: 60$ & 6.74 & 35.9146 & -12 & 5.64 & 36.72 & 35 & & 5.32 & 36.53 & 35.9 & 91 & 4.08 \\
\hline 115 & 211 & 1.20 & 110 & $18: 30$ & 4.52 & 35.9725 & 67 & 7.19 & 34.49 & 35.9 & 20 & 7.27 & 34.22 & 35.9 & 383 & 5.92 \\
\hline 116 & 2110 & 1.74 & 12 & $3: 18$ & 1.35 & 36.1030 & -120 & 3.07 & 51.38 & 36.0998 & -12 & 3.48 & 50.46 & 36.0947 & 830 & 5.49 \\
\hline 117 & 2110 & 1.34 & $5 / 14$ & $3: 21$ & 5.21 & 36.2491 & -120 & 5.00 & 5.24 & 36.2 & & 5.93 & 4.57 & 36.2 & 31 & 6.52 \\
\hline 118 & 2110 & 1.29 & 114 & $18: 47$ & 2.31 & 36.1953 & -120 & 7.36 & 52.46 & 36.1902 & -12 & 7.66 & $\$ 2.60$ & 36.1877 & 530 & 5.98 \\
\hline 19 & 211 & 1.74 & & $20: 15$ & 6.36 & 36.1064 & -12 & 2.75 & 26.43 & 0 & & 3.16 & 25.41 & 36. & 12 & 5.98 \\
\hline 120 & 211 & .00 & & $8: 14$ & 2.24 & 36.1 & -12 & 7.38 & 12.22 & 36 & & 8.15 & 2.30 & 36.1 & & 6.01 \\
\hline 121 & 2110 & 1.96 & 20 & $23: 44$ & 1.35 & 36.0620 & 70 & 0.32 & 1.52 & 36.0 & 45 & 0.03 & 1.31 & 36.0467 & 534 & 3.61 \\
\hline 122 & 21104837 & 1.02 & $6 / 21$ & 0:90 & 0.86 & 36.0053 & -120 & 4.51 & 20.96 & 36.0065 & 627 & 4.91 & 20.75 & 35.9899 & 907 & 6.67 \\
\hline 123 & 2110 & 1.01 & 21 & $1: 55$ & 4.38 & 36.0331 & -120. & 5.02 & 24.42 & 36.0348 & -12 & 4.16 & 4.39 & 36.0172 & 030 & 4.64 \\
\hline 124 & 211 & 1.87 & & $3: 10$ & 9.07 & 36.0678 & & 1.94 & 19.05 & & & 1.24 & 8.74 & 36.0 & 68 & 3.25 \\
\hline 5 & 211 & 0.94 & & $6: 26$ & 8.46 & 36.0678 & -12 & 2.01 & 18.49 & 7 & -12 & 2.45 & 17.91 & 36.0 & 21 & 1.59 \\
\hline 126 & 211 & 1.00 & 25 & 6:90 & 2.60 & 35.8302 & -120 & 5.64 & 22.54 & 35.8295 & 73 & 5.18 & 2.60 & 35.8335 & 798 & 3.77 \\
\hline 127 & 2110 & 2.37 & 26 & $15: 50$ & 9.32 & 36.0350 & -120.5895 & 8.31 & 39.30 & 36.0363 & -120 & 8.53 & 39.15 & 36.0244 & 6056 & 6.92 \\
\hline 128 & 21106056 & 1.89 & $6 / 26$ & $15: 56$ & 9.41 & 36.1015 & -120.6590 & 7.96 & 59.61 & 36.0950 & -120 & 7.61 & 59.04 & 36.0890 & 727 & 8.62 \\
\hline 129 & 2110 & 1.40 & 26 & $16: 46$ & 2.63 & 36.1015 & -120.6 & 7.91 & 12.76 & 36.0918 & -120 & 6.86 & 2.07 & 36.0973 & 615 & 8.98 \\
\hline 130 & 211 & 0.97 & & $20: 40$ & 0.83 & 36.1 & & 7.65 & 11.21 & & & 5.39 & 10.89 & 36.0 & & 8.37 \\
\hline 131 & 2110 & .29 & 27 & $5: 27$ & 2.24 & 35.9940 & -12 & 4.37 & 52.22 & 35.9943 & -12 & 4.85 & 2.08 & 35.9869 & 518 & 1.50 \\
\hline 132 & 2110 & 1.11 & $6 / 27$ & 6:43 & 3.55 & 35.9992 & -120 & 3.14 & 23.56 & 36.0000 & -120 & 3.88 & 23.49 & 35.9868 & .5776 & 4.18 \\
\hline 133 & 21106399 & 1.35 & $2000 / 06 / 27$ & $21: 26$ & 1.77 & 36.2250 & -120.7393 & 7.08 & 32.13 & 36.2170 & -120.7560 & 6.72 & $\beta 2.12$ & 36.2219 & -120.7465 & 5.17 \\
\hline 134 & 21107670 & 1.03 & $2000 / 07 / 04$ & $0: 35$ & 8.92 & 35.9266 & -120.4 & 5.43 & 38.89 & 35.9283 & -120 & 5.43 & $\beta 8.49$ & 35.9194 & 890 & 5.29 \\
\hline 135 & 2110 & 1.18 & & $7: 42$ & 5.02 & 36.0378 & -120 & 4.72 & 4.98 & 36.04 & -120 & 4.46 & 4.62 & 36.0292 & 003 & 2.27 \\
\hline 136 & 2110 & 1.15 & 106 & $7: 31$ & 4.76 & 35.9838 & -120 & 7.48 & 24.68 & 35.9878 & -120 & 7.68 & 24.58 & 35.9747 & 481 & 5.80 \\
\hline 137 & 21108028 & 1.15 & 706 & $7: 37$ & 6.19 & 35.9837 & -120.5350 & 7.47 & 6.19 & 35.9853 & -120.5327 & 7.41 & 6.02 & 35.9736 & -120.5481 & 5.80 \\
\hline 138 & 21108170 & 1.04 & $2000 / 07 / 07$ & $3: 29$ & 6.03 & 36.0107 & -120.5681 & 4.56 & 16.10 & 36.0108 & -120.5700 & 4.05 & 15.99 & 35.9972 & -120.5812 & 2.69 \\
\hline 139 & 21108500 & 1.55 & $2000 / 07 / 09$ & $4: 17$ & 1.16 & 36.0120 & -120.5677 & 4.74 & 11.08 & 36.0127 & -120.5658 & 5.26 & 10.78 & 36.0050 & -120.5808 & 4.52 \\
\hline 140 & 2110 & 1.97 & $2000 / 07 / 09$ & $10: 59$ & 0.80 & 36.1948 & -120.7 & 7.17 & 10.84 & 36.1927 & -120 & 7.74 & 10.76 & 36.1855 & 644 & 6.31 \\
\hline 141 & 21109067 & 1.13 & $7 / 12$ & $9: 10$ & 1.26 & 36.0533 & -120. & 7.73 & 31.31 & 36.0543 & -120 & 7.94 & 31.25 & 36.0399 & 158 & 6.35 \\
\hline 142 & 21109780 & 1.60 & $2000 / 07 / 14$ & $17: 22$ & 4.96 & 36.0395 & -120.6068 & 1.12 & 15.04 & 36.0448 & -120.6000 & 1.65 & 14.71 & 36.0252 & -120.6183 & 4.29 \\
\hline 143 & 21110287 & 1.53 & $2000 / 07 / 16$ & $22: 31$ & 2.39 & 36.0301 & -120.5872 & 4.79 & 2.35 & 36.0295 & -120.5898 & 4.68 & 1.92 & 36.0254 & -120.5876 & 3.11 \\
\hline 144 & 21110308 & 1.74 & $2000 / 07 / 17$ & $4: 25$ & 7.40 & 36.0231 & -120.5855 & 0.40 & 57.48 & 36.0258 & -120.5817 & 0.11 & $\$ 7.19$ & 36.0207 & -120.5906 & 3.22 \\
\hline
\end{tabular}


Appendix II Comparison of VELHYPO relocated events with results of HypoDD and HYPOINVERSE.

\begin{tabular}{|c|c|c|c|c|c|c|c|c|c|c|c|c|c|c|c|c|}
\hline & & & & & & & poDD & & & HYPO & INVERSE & & & & HYPO & \\
\hline $\mathrm{S} / \mathrm{N}$ & Event ID & Mag & $\begin{array}{c}\text { Date } \\
\text { (yy/mm/dd) }\end{array}$ & $\mathrm{h}: \mathrm{mm}$ & \begin{tabular}{|l} 
Time \\
(ss)
\end{tabular} & $\begin{array}{c}\text { Lat } \\
\text { (deg) }\end{array}$ & $\begin{array}{l}\begin{array}{l}\text { Long } \\
\text { (deg) }\end{array} \\
\end{array}$ & $\begin{array}{l}\text { Dept } \\
(\mathrm{km})\end{array}$ & $\begin{array}{l}\begin{array}{l}\text { Time } \\
\text { (ss) }\end{array} \\
\end{array}$ & $\begin{array}{c}\text { Lat } \\
(\mathrm{deg})\end{array}$ & $\begin{array}{l}\begin{array}{l}\text { Long } \\
\text { (deg) }\end{array} \\
\end{array}$ & $\begin{array}{l}\text { Dept } \\
(\mathrm{km})\end{array}$ & \begin{tabular}{|l}
$\begin{array}{l}\text { Time } \\
\text { (ss) }\end{array}$ \\
\end{tabular} & $\begin{array}{c}\text { Lat } \\
\text { (deg) }\end{array}$ & $\begin{array}{l}\begin{array}{l}\text { Long } \\
(\mathrm{deg})\end{array} \\
\end{array}$ & $\begin{array}{l}\text { Dept } \\
(\mathrm{km})\end{array}$ \\
\hline 145 & 21110520 & 1.16 & $2000 / 07 / 17$ & 19:42 & 8.49 & 36.1634 & \begin{tabular}{|l|}
-120.7344 \\
\end{tabular} & 4.95 & 38.48 & \begin{tabular}{|l|}
36.1627 \\
\end{tabular} & -120.7362 & 6.11 & 38.05 & 36.1681 & -120.7241 & 6.40 \\
\hline 146 & 21110804 & 1.26 & $2000 / 07 / 19$ & $1: 54$ & 6.53 & 36.0395 & -120.5946 & 4.47 & 56.54 & \begin{tabular}{|l|}
36.0407 \\
\end{tabular} & -120.5948 & 3.96 & 56.33 & 36.0248 & -120.6109 & 4.15 \\
\hline 147 & 21110816 & 1.17 & $2000 / 07 / 19$ & $3: 32$ & 1.72 & 36.0397 & -120.5942 & 4.64 & 31.71 & 36.0425 & -120.5877 & 4.13 & \$1.42 & 36.0328 & -120.5947 & 2.49 \\
\hline 148 & 21111281 & 1.12 & $2000 / 07 / 21$ & $5: 50$ & 4.79 & 36.0101 & -120.5651 & 5.54 & 34.82 & 36.0122 & -120.5628 & 5.70 & 34.58 & 36.0013 & -120.5743 & 5.08 \\
\hline 149 & 21111715 & 2.00 & $2000 / 07 / 24$ & $8: 41$ & 8.28 & 36.0961 & -120.6625 & 3.61 & 18.15 & 36.1010 & -120.6578 & 4.59 & 7.84 & 36.0925 & -120.6640 & 3.96 \\
\hline 150 & 21111901 & 0.92 & $2000 / 07 / 25$ & $18: 70$ & 8.06 & 35.9648 & -120.5134 & 3.98 & 18.21 & 35.9652 & -120.5158 & 3.78 & 8.08 & 35.9597 & -120.5329 & 1.09 \\
\hline 151 & 2111 & 0.95 & $2000 / 07 / 29$ & 12:50 & 4.38 & 35.9220 & -120.4674 & 5.25 & 14.34 & 35.9190 & -12 & 5.02 & 14.02 & 35.9143 & 904 & 4.55 \\
\hline 152 & 2111 & 1.09 & $2000 / 07 / 29$ & 19:24 & 2.74 & 35.7772 & -120.4444 & 10.76 & 2.72 & 35.7 & 407 & 11.04 & 1.87 & 35.7731 & 527 & 13.70 \\
\hline 153 & 21178944 & 0.94 & $2000 / 07 / 30$ & $0: 32$ & 2.79 & 36.0088 & -120.5839 & 5.44 & 32.72 & 36.0113 & -120.5855 & 5.71 & $\beta 2.50$ & 35.9963 & 5160 & 6.41 \\
\hline 154 & 21114207 & 1.20 & $2000 / 07 / 31$ & 17:47 & 1.77 & 35.8840 & -120.4320 & 10.89 & 21.97 & 35.8848 & -120.4322 & 10.45 & 1.75 & 35.8838 & -120.4454 & 9.95 \\
\hline 155 & 21114751 & 1.39 & $2000 / 08 / 03$ & $12: 26$ & 3.50 & 36.0872 & -120.6499 & 2.82 & 23.42 & 36.0963 & -120.6417 & 4.18 & 3.04 & 36.0845 & 6515 & 4.47 \\
\hline 156 & 2118 & 1.02 & $2000 /$ & $15: 43$ & 3.07 & 35.9786 & -120 & 2.91 & 13.08 & 35. & -12 & 4.20 & 2.80 & 35.9 & 99 & 1.46 \\
\hline 157 & 211 & 0.00 & $2000 / C$ & $2: 45$ & 8.33 & 35.9696 & & 3.03 & 58.41 & 35.9 & & 1.36 & 7.93 & 35.9651 & 478 & 1.48 \\
\hline 158 & 211 & 1.41 & $2000 / 0$ & 19:15 & 1.00 & 36.0360 & 10 & 4.68 & 21.05 & 36.0 & & 4.09 & 20.75 & 36.0 & 117 & 3.31 \\
\hline 159 & 2111 & 1.64 & $2000 / 0$ & $0: 48$ & 9.99 & 36.2719 & -120.8 & 5.64 & 50.00 & 36.2685 & -120 & 6.84 & 9.91 & 36.2712 & 461 & 5.15 \\
\hline 160 & 2118 & 1.10 & $2000 / 08 / 08$ & $7: 60$ & 8.50 & 36.0264 & -120.5878 & 2.54 & 58.51 & 36.0298 & -120. & 2.78 & 58.39 & 36.0184 & -120.5946 & 0.99 \\
\hline 161 & 2118 & 0.00 & $2000 / 0$ & $7: 14$ & 9.74 & 35.9493 & -120.5 & 9.85 & 59.83 & 35.9450 & -12 & 9.34 & 99.73 & 35.9480 & 178 & 8.13 \\
\hline 162 & 211 & 0.94 & & 11:51 & 4.27 & 36.0589 & -12 & 1.93 & 34.30 & & & 3.23 & 33.52 & 36.0 & 27 & 1.90 \\
\hline 163 & 211 & 1.13 & 10 & $15: 10$ & 4.50 & 35.9843 & -12( & 2.42 & 14.49 & & & 3.43 & 14.18 & 35.9 & 34 & 0.97 \\
\hline 164 & 211 & 2.14 & $2000 / 0$ & $15: 24$ & 3.85 & 35.9844 & -120 & 2.49 & 13.89 & 28 & 45 & 4.26 & 3.65 & 35.9770 & 532 & 1.51 \\
\hline 165 & 2118 & 0.00 & 11 & 16:47 & 1.20 & 35.9254 & -120.4767 & 5.06 & 11.23 & 35.9245 & -120 & 4.89 & 0.97 & 35.9203 & 973 & 4.51 \\
\hline 166 & 211 & 0.97 & $2000 / 0$ & $8: 80$ & 7.76 & 35.8931 & -120.4 & 1.15 & 17.66 & 35.8935 & -120 & 1.49 & 7.45 & 35.8992 & 538 & 0.36 \\
\hline 167 & 211 & 1.66 & & $20: 58$ & 6.58 & 35.9986 & -12 & 3.24 & 56.55 & & 78 & 4.11 & 56.29 & 35.9 & 05 & 2.48 \\
\hline 168 & 211 & 1.44 & & $21: 32$ & 7.77 & 36.0711 & -12 & 3.04 & 17.70 & & & 4.04 & 7.45 & 36.0 & 11 & 1.58 \\
\hline 169 & 211 & 1.06 & 16 & 9:30 & 9.09 & 36.1434 & 28 & 5.66 & 39.16 & & 05 & 6.06 & 39.23 & 36.1 & 262 & 5.07 \\
\hline 170 & 2112 & 1.72 & 16 & 17:20 & 2.26 & 35.9991 & -120 & 3.37 & 52.20 & 90 & -12 & 4.54 & 1.71 & 35.9908 & 755 & 4.55 \\
\hline 171 & 2112 & 1.29 & 18 & $12: 54$ & 1.05 & 36.0049 & -120 & 4.55 & 31.01 & 36. & -12 & 4.48 & 30.41 & 35.9998 & 660 & 4.51 \\
\hline 172 & 211 & 0.95 & 20 & 9:50 & 9.40 & 36.0065 & -120 & 5.13 & 29.23 & & 42 & 6.35 & 8.80 & 35.9970 & 759 & 5.75 \\
\hline 173 & 211 & 1.32 & & 11:60 & 6.30 & 36.2224 & -12 & 6.28 & 26.25 & & 28 & 5.87 & 26.09 & 36.2 & 29 & 5.21 \\
\hline 174 & 211 & 1.42 & & 18:00 & 5.68 & 35.8911 & -12 & 11.19 & 15.74 & & & 10.77 & 15.55 & 35.8 & 48 & 9.96 \\
\hline 175 & 211 & 1.39 & 22 & $0: 39$ & 3.12 & 36.0108 & -12 & 3.15 & 3.01 & & & 4.14 & 2.48 & 35.9 & 660 & 4.35 \\
\hline 176 & 2121 & 2.10 & 23 & $4: 44$ & 9.58 & 36.0025 & -120 & 4.59 & 29.63 & & & 5.26 & 9.20 & 35.9969 & 701 & 4.61 \\
\hline 177 & 2112 & 1.42 & 2000 & $5: 28$ & 3.31 & 35.9613 & -120 & 3.16 & 43.14 & 35.9608 & -12 & 4.12 & 12.96 & 35.9514 & 299 & 2.57 \\
\hline 178 & 211 & 0.95 & 26 & 10:14 & 2.04 & 35.8853 & 27 & 6.41 & 2.12 & & 2 & 6.28 & 1.96 & 35.8 & 29 & 4.66 \\
\hline 179 & 211 & 1.16 & & 21:11 & 0.20 & 35.9986 & & 2.98 & 50.03 & & & 2.78 & 49.79 & 35.9 & 58 & 2.51 \\
\hline 180 & 211 & 1.14 & 27 & $1: 30$ & 1.89 & 35.9280 & & 5.01 & 11.97 & & & 5.07 & 1.20 & 35.9 & 887 & 5.78 \\
\hline 181 & 2112 & 1.37 & $2000 / 08 / 27$ & 18:11 & 6.55 & 36.2885 & -120.7828 & 7.34 & 16.70 & & -12 & 8.78 & 6.39 & 36.2823 & 857 & 9.00 \\
\hline 182 & 2112 & 1.40 & $/ 28$ & 6:32 & 2.60 & 36.2606 & -12 & 8.54 & 12.49 & & & 9.15 & 2.23 & 36.2 & 281 & 9.52 \\
\hline 183 & 2112 & 1.46 & $/ 31$ & $9: 10$ & 6.53 & 35.8811 & -120 & 10.23 & 36.58 & 35.8 & -12 & 10.12 & 36.49 & 35.8766 & 51 & 8.99 \\
\hline 184 & 211 & 1.32 & & $1: 52$ & 8.03 & 36.2326 & -12 & 7.50 & 28.13 & & & 7.84 & 8.15 & 36.2 & 977 & 6.10 \\
\hline 185 & 211 & 1.12 & & $10: 13$ & 6.82 & 36.0337 & & 0.57 & 16.82 & & & 0.25 & 46.44 & 36.0 & 221 & 5.48 \\
\hline 186 & 2118 & 0.00 & 03 & 15:80 & 4.85 & 35.9423 & -12 & 13.86 & 34.95 & & & 3.54 & 34.79 & 35. & 107 & 11.93 \\
\hline 187 & 211 & 0.00 & 03 & 15:54 & 7.37 & 35.9579 & -120 & 11.01 & 7.48 & & & 10.55 & 7.51 & 35.9 & 269 & 8.87 \\
\hline 188 & 2112 & 1.41 & 103 & $22: 27$ & 8.94 & 35.9383 & -120.4 & 5.60 & 58.94 & 35. & -120 & 5.62 & 58.45 & 35.9309 & 986 & 5.56 \\
\hline 189 & 211 & 1.02 & & $23: 17$ & 9.07 & 35.9477 & -12 & 4.76 & 19.06 & & -1 & 4.60 & 8.47 & 35. & 122 & 4.83 \\
\hline 190 & 211 & 1.02 & & 10:80 & 4.20 & 36.0338 & 99 & 4.61 & $\$ 4.19$ & & & 4.16 & 44.03 & 36.0 & 35 & 2.09 \\
\hline 191 & 2112 & 1.58 & 200 & 15:80 & 2.05 & 36.2686 & 49 & 8.17 & 32.22 & & -12 & 8.07 & 32.40 & 36.2633 & 210 & 5.31 \\
\hline 192 & 2118 & 1.11 & $2000 /($ & $22: 40$ & 1.90 & 36.0246 & -120 & 4.99 & $\$ 1.94$ & 73 & 68 & 4.52 & 1.93 & 36.0172 & 821 & 2.45 \\
\hline 193 & 21123865 & 1.35 & $\angle 06$ & $5: 41$ & 3.56 & 36.1253 & -120 & 7.84 & 13.61 & & -12 & 7.40 & 2.87 & 36.1 & 998 & 8.37 \\
\hline 194 & 21123888 & 1.81 & & $10: 40$ & 1.88 & 35.9579 & -120 & 1.15 & 11.87 & & -120 & 11.53 & 11.87 & 35.9480 & 260 & 9.00 \\
\hline 195 & 211 & 1.16 & & 13:90 & 5.50 & 36.0438 & -121 & 4.60 & 15.49 & & -12 & 4.26 & 5.04 & 36.0362 & 027 & 3.38 \\
\hline 196 & & 2.37 & & $16: 40$ & 4.37 & 35.8441 & -120 & 4.19 & 54.32 & & & 4.49 & 3.92 & 35.8458 & 850 & 4.07 \\
\hline 197 & 2112 & 1.13 & & 20:24 & 9.54 & 35.8447 & 30 & 4.20 & 39.59 & 43 & 62 & 3.90 & $\beta 9.03$ & 35.8460 & 845 & 4.36 \\
\hline 198 & 2112 & 2.35 & 08 & $22: 10$ & 0.97 & 36.0493 & -120.6071 & 3.55 & 20.95 & 460 & -120 & 5.50 & 0.09 & 36.0130 & 558 & 7.54 \\
\hline 199 & 21124426 & 1.57 & 09 & $20: 23$ & 8.02 & 35.7791 & -120.3289 & 8.50 & 38.03 & \begin{tabular}{|l|}
35.7778 \\
\end{tabular} & -120 & 8.67 & 37.79 & 35.7786 & 325 & 9.00 \\
\hline 200 & 2112 & 1.27 & & $20: 42$ & 3.34 & 35.7788 & -120.3285 & 8.48 & 33.38 & 67 & -120 & 8.59 & 33.10 & 35.7748 & 317 & 9.00 \\
\hline 201 & 2112 & 2.35 & 2000 & $11: 15$ & 8.06 & 36.0299 & -120 & 4.65 & 18.02 & 17 & -120 & 5.24 & 47.75 & 36.0209 & 008 & 4.31 \\
\hline 202 & 21124484 & 1.85 & & $11: 27$ & 7.96 & 36.0291 & -120.5871 & 4.65 & 17.90 & & -12 & 5.15 & 7.74 & 36.0223 & 004 & 2.60 \\
\hline 203 & 21181739 & 0.00 & $2000 / 09 / 11$ & $8: 26$ & 9.30 & 35.9790 & -120.5340 & 11.55 & 29.36 & 35.9747 & -120.5410 & 11.91 & 29.31 & 35.9634 & 602 & 9.63 \\
\hline 204 & 21181742 & 0.95 & $2000 / 09 / 12$ & $3: 80$ & 1.87 & 36.0663 & -120.6350 & 1.74 & 11.85 & 36.0683 & -120. & 1.66 & 1.62 & 36.0583 & -120.6382 & 0.94 \\
\hline 205 & 2112 & 1.29 & & 18:00 & 2.10 & 36.2708 & -120 & 4.84 & 32.08 & 28 & -120. & 6.34 & $\beta 1.95$ & 36.2590 & 552 & 5.30 \\
\hline 206 & 2112 & 1.50 & 13 & $4: 53$ & 6.26 & 36.0138 & -120 & 4.82 & 36.28 & & -120 & 5.37 & 36.00 & 36.0073 & 842 & 4.54 \\
\hline 207 & 21125208 & 1.19 & $2000 / 09 / 14$ & $3: 22$ & 0.92 & 36.0649 & -120. & 2.23 & 20.89 & 88 & -120 & 2.56 & 0.33 & 36.0544 & 351 & 0.51 \\
\hline 208 & 21125239 & 1.40 & $2000 / 09 / 14$ & 10:90 & 7.52 & 36.2365 & -120.8017 & 7.72 & 7.50 & 36.2360 & -120.8040 & 8.58 & 7.41 & 36.2490 & -120.7976 & 7.22 \\
\hline 209 & 21125247 & 1.38 & $2000 / 09 / 14$ & 12:26 & 3.83 & 36.1006 & -120.6604 & 4.72 & 13.75 & 36.1058 & -120.6552 & 5.04 & 3.58 & 36.0928 & -120.6617 & 4.59 \\
\hline 210 & 2112 & 1.59 & $2000 / 09 / 14$ & 18:21 & 2.10 & 36.0692 & -120 & 2.86 & 52.08 & 38 & -120 & 3.42 & 1.67 & 36.0584 & 379 & 1.52 \\
\hline 211 & 21125305 & 1.02 & $9 / 14$ & $22: 42$ & 5.24 & 36.0359 & -120. & 4.84 & 5.22 & 85 & -120 & 4.33 & 4.88 & 36.0273 & 009 & 0.67 \\
\hline 212 & 21125419 & 1.41 & $2000 / 09 / 15$ & $23: 49$ & 1.01 & 36.1963 & -120.7606 & 6.11 & 51.00 & 36.1895 & -120.7708 & 6.22 & $\$ 1.11$ & 36.1900 & -120.7649 & 3.57 \\
\hline 213 & 21125455 & 1.22 & $2000 / 09 / 16$ & $6: 24$ & 3.35 & 36.0033 & -120.5581 & 6.00 & 33.38 & 36.0038 & -120.5560 & 5.94 & 33.31 & 35.9923 & -120.5705 & 4.81 \\
\hline 214 & 21125505 & 2.62 & $2000 / 09 / 16$ & 15:50 & 6.03 & 36.0039 & -120.5622 & 4.61 & 6.01 & 36.0045 & -120.5618 & 5.32 & 5.48 & 35.9965 & -120.5766 & 5.13 \\
\hline 215 & 21181749 & 1.09 & $2000 / 09 / 16$ & 17:21 & 0.97 & 36.0019 & -120.5632 & 4.90 & 10.99 & 36.0020 & -120.5645 & 5.77 & 0.84 & 35.9900 & -120.5772 & 4.80 \\
\hline & 21125707 & 1.39 & $2000 / 09 / 18$ & $7: 53$ & 2.69 & 36.2315 & -120.7958 & 8.53 & $\$ 2.95$ & 36.2128 & -120.8063 & 8.02 & 12.87 & 36.2312 & -120.7991 & 7.86 \\
\hline
\end{tabular}


Appendix II Comparison of VELHYPO relocated events with results of HypoDD and HYPOINVERSE.

\begin{tabular}{|c|c|c|c|c|c|c|c|c|c|c|c|c|c|c|c|c|}
\hline & & & & & & & poDD & & & HY & INVERSE & & & & HYPO & \\
\hline $\mathrm{S} / \mathrm{N}$ & Event ID & Mag & $\begin{array}{c}\text { Date } \\
\text { (yy/mm/dd) }\end{array}$ & $\mathrm{h}: \mathrm{mm}$ & \begin{tabular}{|l} 
Time \\
(ss)
\end{tabular} & $\begin{array}{c}\text { Lat } \\
\text { (deg) }\end{array}$ & $\begin{array}{l}\begin{array}{l}\text { Long } \\
\text { (deg) }\end{array} \\
\end{array}$ & $\begin{array}{l}\text { Dept } \\
(\mathrm{km})\end{array}$ & $\begin{array}{l}\begin{array}{l}\text { Time } \\
\text { (ss) }\end{array} \\
\end{array}$ & $\begin{array}{c}\text { Lat } \\
(\mathrm{deg})\end{array}$ & $\begin{array}{l}\begin{array}{l}\text { Long } \\
\text { (deg) }\end{array} \\
\end{array}$ & $\begin{array}{l}\text { Dept } \\
(\mathrm{km})\end{array}$ & \begin{tabular}{|l}
$\begin{array}{l}\text { Time } \\
\text { (ss) }\end{array}$ \\
\end{tabular} & $\begin{array}{c}\text { Lat } \\
\text { (deg) }\end{array}$ & $\begin{array}{l}\begin{array}{l}\text { Long } \\
(\mathrm{deg})\end{array} \\
\end{array}$ & $\begin{array}{l}\text { Dept } \\
(\mathrm{km})\end{array}$ \\
\hline 217 & 21125839 & 1.49 & \begin{tabular}{|l|}
$2000 / 09 / 19$ \\
\end{tabular} & $2: 39$ & 5.16 & 36.2318 & \begin{tabular}{|l|}
-120.7951 \\
\end{tabular} & 8.88 & 5.31 & \begin{tabular}{|l|}
36.2253 \\
\end{tabular} & -120.8075 & 8.88 & 5.25 & 36.2207 & -120.8175 & 7.25 \\
\hline 218 & 21126003 & 1.26 & $2000 / 09 / 20$ & $3: 23$ & 1.29 & 35.8790 & -120.4262 & 10.04 & 11.30 & 35.8753 & -120.4302 & 9.69 & 0.75 & 35.8832 & -120.4385 & 0.17 \\
\hline 219 & 30222216 & 2.78 & $2000 / 09 / 21$ & 18:70 & 4.22 & 35.8494 & -120.3960 & 6.66 & 34.15 & 35.8468 & -120.3948 & 6.84 & \$3.87 & 35.8466 & -120.4044 & 6.40 \\
\hline 220 & 30222214 & 3.28 & $2000 / 09 / 21$ & 18:80 & 8.54 & 35.8501 & -120.3969 & 6.70 & 58.63 & 35.8472 & -120.3955 & 6.91 & 8.28 & 35.8470 & -120.4051 & 6.69 \\
\hline 221 & 30222215 & 2.47 & $2000 / 09 / 21$ & 18:90 & 9.82 & 35.8468 & -120.3933 & 6.66 & 59.76 & 35.8462 & -120.3932 & 6.79 & 59.57 & 35.8464 & -120.4026 & 6.02 \\
\hline 222 & 21126282 & 1.11 & $2000 / 09 / 21$ & $18: 18$ & 8.00 & 36.0225 & -120.5804 & 4.65 & 57.96 & 36.0247 & -120.5780 & 5.14 & 87.39 & 36.0172 & -120.5863 & 4.57 \\
\hline 223 & 2112 & 1.10 & $2000 / 09 / 21$ & 18:28 & 5.21 & 35.9908 & -120.5491 & 4.89 & 55.25 & 35.9922 & -12 & 5.05 & 54.90 & 35.9814 & 586 & 4.36 \\
\hline 224 & 21126687 & 1.38 & $2000 / 0$ & $5: 54$ & 6.38 & 36.2461 & -120.7430 & 5.42 & 56.63 & 36.2388 & 588 & 5.42 & 56.59 & 36.2427 & 487 & 2.76 \\
\hline 225 & 21181763 & 0.95 & $2000 / 09 / 24$ & 12:32 & 5.47 & 36.0366 & -120.6063 & 0.11 & 55.61 & 36.0383 & 990 & 0.03 & 54.85 & 36.0331 & -120.6048 & 0.14 \\
\hline 226 & 21126805 & 1.56 & $2000 / 09 / 25$ & $6: 47$ & 0.48 & 36.0153 & -120.5722 & 4.53 & 0.62 & 36.0158 & -120.5723 & 5.23 & 0.37 & 36.0090 & -120.5854 & 4.10 \\
\hline 227 & 21126815 & 1.53 & $2000 / 09 / 25$ & $8: 54$ & 1.83 & 35.9954 & -120.5538 & 5.05 & 31.84 & 35.9942 & -120.5543 & 5.66 & 31.52 & 35.9858 & 684 & 4.68 \\
\hline 228 & 2112 & 1.12 & $2000 / 0$ & 8:58 & 6.96 & 35.9951 & -120 & 5.08 & 16.86 & 35.9 & 18 & 5.45 & 46.82 & 35.9865 & 90 & 1.50 \\
\hline 229 & 211 & 0.00 & $2000 / 0$ & 15:00 & 7.01 & 35.8945 & 71 & 2.27 & 37.13 & 35.9013 & & 9.65 & 37.18 & 35.9056 & 671 & 9.23 \\
\hline 230 & 2112 & 1.42 & $2000 / 1$ & $3: 13$ & 3.08 & 35.8335 & -12 & 7.50 & 23.35 & 35.8553 & & 6.79 & 3.22 & 35.8864 & 341 & 7.16 \\
\hline 231 & 21128050 & 1.37 & $2000 / 1$ & $4: 49$ & 3.76 & 35.8490 & -120.3 & 6.64 & 13.76 & 35.8465 & -12 & 6.59 & 4.47 & 35.8478 & 055 & 6.56 \\
\hline 232 & 30222260 & 1.41 & $2000 / 10 / 02$ & $4: 49$ & 1.33 & 35.8719 & -120.3390 & 9.42 & 51.39 & 35.8683 & -120 & 9.19 & 51.73 & 35.8528 & -120.3963 & 6.76 \\
\hline 233 & 2112 & 1.53 & $2000 / 1$ & 10:20 & 3.08 & 36.0130 & -120. & 4.82 & 13.04 & 36.0135 & -12 & 5.38 & 2.73 & 36.0053 & 811 & 4.72 \\
\hline 234 & 211 & .11 & & 14:51 & 0.42 & 36.0151 & -12 & 4.69 & 30.44 & 53 & 27 & 4.98 & 30.41 & 36.0 & 45 & 2.88 \\
\hline 235 & 211 & 1.92 & 03 & $21: 19$ & 3.54 & 36.1906 & -12 & 2.20 & 33.66 & 36.1 & & 3.08 & 33.37 & 36.1 & 536 & 0.50 \\
\hline 236 & 2112 & 1.27 & $2000 / 1$ & $1: 13$ & 6.06 & 36.0000 & -120 & 12.31 & 16.05 & 36.0030 & -12 & 12.37 & 16.02 & 35.9886 & 616 & 10.28 \\
\hline 237 & 2112 & 1.92 & $2000 /$ & $4: 47$ & 2.02 & 36.0108 & -120.5 & 4.79 & 11.97 & 36.0113 & -120 & 5.61 & 1.71 & 36.0018 & 822 & 4.45 \\
\hline 238 & 3022 & 1.11 & $2000 /$ & $13: 45$ & 5.51 & 36.0025 & -120 & 4.62 & 5.46 & 36.0038 & -12 & 5.32 & 5.16 & 35.9927 & 724 & 4.79 \\
\hline 239 & 211 & 1.11 & 08 & 17:39 & 0.07 & 36.0048 & -12 & 5.53 & 10.01 & 36. & 3 & 6.12 & 9.76 & 35.9 & 50 & 5.75 \\
\hline 240 & 211 & 1.25 & & $7: 22$ & 6.89 & 36.0059 & -12 & 6.76 & 36.91 & 36. & & 6.78 & 36.67 & 35.9 & 74 & 5.58 \\
\hline 241 & 211 & 1.37 & 09 & $20: 27$ & 1.89 & 35.9622 & -12 & 10.89 & 1.92 & 35.9 & -12 & 11.03 & 2.07 & 35.9507 & 330 & 8.26 \\
\hline 242 & 211 & 1.12 & 10 & $1: 39$ & 7.92 & 36.0126 & -120 & 4.47 & 27.90 & 36.0 & & 4.38 & 7.29 & 36.0019 & 026 & 7.81 \\
\hline 243 & 211 & 1.92 & 112 & $15: 36$ & 9.40 & 36.0480 & -120 & 4.26 & 59.29 & 36.0 & -12 & 4.69 & 59.07 & 36.0396 & 187 & 2.50 \\
\hline 244 & 211 & 0.95 & 13 & $21: 50$ & 1.77 & 35.8946 & -12 & 6.37 & 1.76 & 68 & -1 & 6.32 & 1.81 & 35.8 & 02 & 4.24 \\
\hline 245 & 211 & 1.35 & & 16:21 & 0.51 & 36.0568 & -12 & 6.41 & 10.45 & 36 & & 6.55 & 0.57 & 36. & 80 & 2.50 \\
\hline 246 & 211 & 1.07 & & $5: 54$ & 6.18 & 35.7966 & -12 & 1.59 & 6.29 & 35.7 & & 10.24 & 6.34 & 35.7 & 85 & 0.59 \\
\hline 247 & 2112 & 1.29 & 15 & 14:26 & 9.01 & 35.7964 & -120 & 11.57 & 9.08 & 35.7 & & 1.43 & 9.03 & 35.7 & 535 & 11.15 \\
\hline 248 & 2112 & 1.54 & 15 & $20: 30$ & 5.91 & 35.7967 & -120 & 11.61 & 16.01 & 35.7 & & 11.73 & 6.00 & 35.7964 & 18 & 10.80 \\
\hline 249 & 21130021 & 1.67 & 2000 & $5: 47$ & 2.77 & 35.9429 & -120.4885 & 10.98 & 32.75 & 35.9 & -12 & 11.05 & $\beta 2.82$ & 35.9329 & 19 & 9.00 \\
\hline 250 & 211 & 1.11 & 17 & $6: 44$ & 9.77 & 36.0207 & 38 & 4.63 & 59.66 & 36 & 22 & 4.93 & 59.25 & 36. & 10 & 4.94 \\
\hline 251 & 211 & 1.14 & & $3: 28$ & 0.09 & 35.9933 & -12 & 4.96 & 20.09 & & & 5.23 & 19.99 & 35.9 & 03 & 2.86 \\
\hline 252 & 211 & 1.31 & 18 & $7: 25$ & 1.44 & 36.2482 & 60 & 8.73 & 11.47 & & & 9.19 & 1.56 & 36.2 & 90 & 7.15 \\
\hline 253 & 2113 & 1.36 & $2000 / 10 / 18$ & 12:44 & 2.93 & 35.9426 & -120 & 11.00 & 2.93 & 35.9 & -12 & 11.06 & 3.18 & 35.9 & 10 & 8.46 \\
\hline 254 & 211 & 0.00 & $/ 19$ & $0: 40$ & 9.74 & 36.0552 & -12 & 5.12 & 49.74 & & & 5.24 & 9.73 & 36.0 & 16 & 2.13 \\
\hline 255 & 2113 & 1.11 & $/ 24$ & 18:18 & 4.71 & 35.9288 & -120 & 5.26 & 34.76 & 35.9252 & -12 & 5.15 & 34.05 & 35.9207 & 904 & 5.85 \\
\hline 256 & 211 & 0.94 & 25 & $0: 54$ & 6.45 & 36.0450 & -12 & 5.06 & 16.49 & 60 & & 4.73 & 6.46 & 36. & 44 & 1.07 \\
\hline 257 & 211 & 1.14 & & $1: 11$ & 0.18 & 36.0389 & & 4.37 & 30.23 & 36. & & 3.24 & 29.55 & 36.0 & 56 & 6.43 \\
\hline 258 & 211 & 0.94 & 25 & $1: 15$ & 2.94 & 36.0452 & & 5.07 & 12.89 & & & 5.43 & 2.98 & 36.0 & 64 & 2.29 \\
\hline 259 & 2113 & 1.03 & 25 & $3: 29$ & 5.53 & 36.0392 & -12 & 4.52 & 55.54 & & & 3.93 & 5.40 & 36.0 & 30 & 0.69 \\
\hline 260 & 2113 & 1.23 & 25 & $5: 19$ & 9.44 & 36.0409 & -120 & 4.66 & 9.46 & 36.0425 & -12 & 4.20 & 9.15 & 36.0 & 015 & 2.32 \\
\hline 261 & 211 & .22 & & $1: 52$ & 4.99 & 36.0425 & -12 & 4.57 & 35.05 & & & 4.26 & 34.53 & 36. & 980 & 3.73 \\
\hline 262 & 211 & 1.33 & & 11:16 & 4.23 & 36.0 & -12 & 4.67 & 34.25 & & -1 & 5.05 & \$3.87 & 36.0 & 25 & 4.98 \\
\hline 263 & 2113 & 0.94 & 11 & 16:58 & 0.38 & 36.0499 & -120 & 4.64 & 30.42 & & & 4.13 & 30.26 & 36.0 & 50 & 5.56 \\
\hline 264 & 2113 & 1.15 & $2000 / 11 / 03$ & $3: 48$ & 3.04 & 36.0394 & -120 & 4.60 & 13.02 & 27 & 20 & 4.36 & 2.91 & 36.0300 & 945 & 0.92 \\
\hline 265 & 2113 & 1.27 & $111 / 03$ & $20: 53$ & 2.91 & 36.2311 & -120 & 7.50 & 23.00 & & -12 & 7.69 & 3.05 & 36.2209 & 57 & 5.96 \\
\hline 266 & 211 & 0.00 & 104 & 13:80 & 8.29 & 36.0575 & -120 & 6.60 & 8.31 & 36.0 & -12 & 6.35 & 7.89 & 36.0488 & 160 & 6.17 \\
\hline 267 & 211 & 1.22 & & $5: 50$ & 3.55 & 36.0378 & -121 & 4.73 & 13.54 & & -12 & 4.41 & 43.40 & 36.0281 & 006 & 1.97 \\
\hline 268 & 2113 & 1.31 & & $7: 10$ & 8.39 & 36.0228 & 007 & 4.64 & 28.38 & 36.0250 & & 4.52 & 8.18 & 36.0165 & 900 & 2.42 \\
\hline 269 & 2113 & 1.19 & 06 & 17:24 & 3.16 & 36.0001 & 17 & 3.34 & 3.17 & & 10 & 4.48 & 2.80 & 35.9916 & 726 & 4.26 \\
\hline 270 & 2113 & 1.41 & 107 & $10: 50$ & 6.49 & 36.2709 & -120.8426 & 5.95 & 26.45 & 36.2767 & -12 & 7.65 & 6.59 & 36.2751 & 386 & 4.90 \\
\hline 271 & 21185679 & 1.09 & 08 & $6: 13$ & 7.58 & 35.9706 & -120.5207 & 3.94 & 17.56 & 35.9717 & -120 & 4.18 & 7.31 & 35.9627 & 384 & 0.91 \\
\hline 272 & 2113 & 1.34 & 112 & $20: 37$ & 6.28 & 36.2712 & -120.8426 & 5.95 & 16.37 & 36.2682 & -120 & 7.40 & 15.97 & 36.2951 & 229 & 8.81 \\
\hline 273 & 2118 & 0.97 & 14 & $1: 29$ & 3.79 & 36.0990 & -120 & 9.35 & 53.93 & 36.0973 & -120 & 8.00 & 3.47 & 36.0892 & 718 & 8.82 \\
\hline 274 & 21185701 & 1.09 & 200 & $17: 70$ & 7.77 & 36.0091 & -120.5651 & 6.15 & 57.67 & 36.0082 & -12 & 7.22 & 87.44 & 35.9967 & 878 & 6.59 \\
\hline 275 & 21134222 & 1.45 & $2000 / 11 / 15$ & 18:41 & 7.74 & 36.2320 & -120.7957 & 8.45 & 47.79 & 36.2255 & -120 & 8.57 & 4.66 & 36.2221 & 042 & 7.84 \\
\hline 276 & 21134493 & 1.54 & $2000 / 11 / 17$ & 14:18 & 7.53 & 36.0355 & -120.5994 & 1.99 & 57.52 & 36.0405 & -120.5913 & 3.18 & 56.82 & 36.0292 & 099 & 0.26 \\
\hline 277 & 2113 & 1.36 & & $14: 47$ & 9.93 & 36.0350 & -120 & 1.85 & 19.91 & 33 & -120 & 2.23 & 19.45 & 36.0294 & 976 & 0.64 \\
\hline 278 & 3022 & 1.67 & 18 & 18:43 & 2.05 & 36.0596 & -120 & 0.03 & 32.02 & & -120 & 0.19 & $\beta 2.51$ & 36.0312 & 323 & 4.26 \\
\hline 279 & 2113 & 1.16 & & 19:54 & 3.94 & 36.0596 & -120.6081 & 10.04 & 43.93 & 36.0 & 110 & 10.39 & 4.05 & 36.0379 & 293 & 6.44 \\
\hline 280 & 21187360 & 0.00 & $2000 / 11 / 19$ & $0: 21$ & 8.25 & 36.0608 & -120.6120 & 9.43 & 28.41 & 36.0605 & -120.6113 & 8.40 & 8.32 & 36.0481 & -120.6208 & 7.95 \\
\hline 281 & 21134813 & 1.49 & $2000 / 11 / 19$ & 10:23 & 2.23 & 35.8448 & -120.3919 & 6.61 & 2.16 & 35.8425 & -120.3908 & 6.85 & 2.06 & 35.8438 & -120.3964 & 5.88 \\
\hline 282 & 2113 & 0.94 & $2000 / 11 / 19$ & 13:80 & 6.64 & 36.0483 & -120. & 1.96 & 16.44 & 36.0 & -120 & 3.90 & 5.66 & 36.0731 & 790 & 2.46 \\
\hline 283 & 21134960 & 1.45 & $2000 /$ & $5: 54$ & 5.95 & 35.9425 & 382 & 0.28 & 6.09 & 35.9417 & -120 & 10.40 & 6.34 & 35.9309 & 100 & 7.66 \\
\hline 284 & 21134962 & 1.27 & $2000 / 11 / 20$ & $5: 57$ & 5.04 & 35.9426 & -120.4883 & 10.25 & 35.05 & 35.9417 & -120.4853 & 9.60 & 35.03 & 35.9309 & -120.5114 & 8.56 \\
\hline 285 & 21134966 & 2.12 & $2000 / 11 / 20$ & $6: 27$ & 0.35 & 35.9420 & -120.4877 & 10.30 & 10.35 & 35.9412 & -120.4882 & 10.36 & 0.59 & 35.9320 & -120.5082 & 7.46 \\
\hline 286 & 21135411 & 1.88 & $2000 / 11 / 23$ & $0: 20$ & 9.64 & 36.2807 & -120.7932 & 3.99 & 19.33 & 36.2963 & -120.7943 & 5.40 & 0.15 & 36.2508 & -120.8095 & 4.14 \\
\hline 287 & 21135479 & 1.27 & $2000 / 11 / 23$ & 17:28 & 7.81 & 36.1027 & -120.6591 & 7.95 & 27.73 & 36.1048 & -120.6557 & 7.66 & 7.04 & 36.0896 & -120.6699 & 9.00 \\
\hline & 21187383 & 0.00 & $2000 / 11 / 23$ & 19:13 & 3.34 & 36.0193 & -120.5716 & 10.09 & 23.41 & 36.0198 & -120.5737 & 10.40 & 3.46 & 36.0045 & -120.5944 & 8.82 \\
\hline
\end{tabular}


Appendix II Comparison of VELHYPO relocated events with results of HypoDD and HYPOINVERSE.

\begin{tabular}{|c|c|c|c|c|c|c|c|c|c|c|c|c|c|c|c|c|}
\hline \multirow[b]{2}{*}{$\mathrm{S} / \mathrm{N}$} & \multirow[b]{2}{*}{ Event ID } & \multirow[b]{2}{*}{ Mag } & \multirow[b]{2}{*}{$\begin{array}{c}\text { Date } \\
\text { (yy/mm/dd) }\end{array}$} & \multirow[b]{2}{*}{ hh:mm } & \multicolumn{4}{|c|}{ hypoDD } & \multicolumn{4}{|c|}{ HYPOINVERSE } & \multicolumn{4}{|c|}{ VELHYPO } \\
\hline & & & & & \begin{tabular}{|l} 
Time \\
(ss)
\end{tabular} & $\begin{array}{c}\text { Lat } \\
\text { (deg) }\end{array}$ & $\begin{array}{l}\begin{array}{l}\text { Long } \\
(\mathrm{deg})\end{array} \\
\end{array}$ & $\begin{array}{l}\text { Dept } \\
(\mathrm{km})\end{array}$ & $\begin{array}{l}\begin{array}{l}\text { Time } \\
\text { (ss) }\end{array} \\
\end{array}$ & $\begin{array}{c}\text { Lat } \\
\text { (deg) }\end{array}$ & $\begin{array}{l}\begin{array}{l}\text { Long } \\
\text { (deg) }\end{array} \\
\end{array}$ & $\begin{array}{l}\text { Dept } \\
(\mathrm{km})\end{array}$ & \begin{tabular}{|l}
$\begin{array}{l}\text { Time } \\
\text { (ss) }\end{array}$ \\
\end{tabular} & $\begin{array}{c}\text { Lat } \\
\text { (deg) }\end{array}$ & $\begin{array}{l}\begin{array}{l}\text { Long } \\
(\mathrm{deg})\end{array} \\
\end{array}$ & $\begin{array}{l}\text { Dept } \\
(\mathrm{km})\end{array}$ \\
\hline 289 & 21135561 & 1.11 & $2000 / 11 / 23$ & $23: 59$ & 9.24 & 36.0116 & 20.5693 & 4.51 & 19.37 & 36.0132 & -120.5680 & 4.88 & 49.03 & 36.0045 & -120.5652 & 1.49 \\
\hline 290 & 21135580 & .24 & $2000 / 11 / 24$ & $4: 20$ & 8.98 & 35.8482 & -120.3470 & 7.47 & 9.08 & 35.8772 & -120.3538 & 7.13 & 9.59 & 35.8607 & -120.4074 & 3.70 \\
\hline 291 & 21135660 & 1.14 & $2000 / 11 / 24$ & $15: 20$ & 8.64 & 35.9283 & -120.4770 & 4.93 & 8.65 & 35.9290 & -120.4758 & 4.82 & 7.96 & 35.9237 & -120.4905 & 4.74 \\
\hline 292 & 21135730 & 1.69 & $2000 / 11 / 24$ & $22: 20$ & 8.24 & 36.1487 & -120.7248 & 3.34 & 48.26 & 36.1453 & -120.7293 & 4.16 & 47.33 & 36.1346 & -120.7371 & 6.99 \\
\hline 293 & 21136045 & 2.01 & $2000 / 11 / 26$ & $10: 60$ & 9.95 & 36.2795 & -120.8538 & 5.57 & 0.06 & 36.2720 & -120.8627 & 6.71 & 0.00 & 36.2768 & -120.8634 & 5.51 \\
\hline 294 & 21136128 & 1.19 & $2000 / 11 / 26$ & $22: 41$ & 8.46 & 35.8716 & -120.3100 & 11.01 & 8.37 & 35.8673 & -120.3167 & 10.84 & 8.59 & 35.8671 & -120.3343 & 9.22 \\
\hline 295 & 21136526 & 2.00 & $2000 / 11 / 30$ & $1: 58$ & 5.29 & 35.9288 & -120.4779 & 4.91 & 15.36 & 35.9273 & -120.4768 & 5.17 & 5.01 & 35.9233 & 397 & 4.62 \\
\hline 296 & 21136531 & 1.73 & $2000 / 1$ & $3: 70$ & 0.57 & 36.2410 & -120.8016 & 5.93 & 50.67 & 36.2327 & -120.8123 & 6.53 & $\$ 0.73$ & 36.2401 & 043 & 4.55 \\
\hline 297 & 21136537 & 1.02 & $2000 / 11 / 30$ & $6: 14$ & 8.78 & 35.8217 & 692 & 5.19 & 58.66 & 35.8215 & 3683 & 5.27 & 88.77 & 35.8245 & 703 & 3.92 \\
\hline 298 & 21136545 & 2.95 & $2000 / 11 / 30$ & 14:80 & 4.18 & 35.9062 & -120.4501 & 6.05 & 4.12 & 35.9055 & -120.4488 & 6.22 & 3.99 & 35.9057 & -120.4579 & 4.37 \\
\hline 299 & 2113 & 1.11 & $2000 / 12 / 01$ & $11: 11$ & 8.98 & 36.0069 & -120.5627 & 5.49 & 38.97 & 36.0075 & -120.5615 & 5.98 & 38.76 & 35.9965 & 5744 & 5.04 \\
\hline 300 & 2113 & 1.29 & $2000 / 1$ & $11: 36$ & 8.60 & 35.9621 & -120 & 0.91 & 28.63 & 35.9620 & 098 & 10.84 & 8.82 & 35.9527 & 293 & 7.58 \\
\hline 301 & 211 & 1.30 & 02 & $14: 48$ & 4.34 & 36.2404 & 07 & 5.81 & 24.37 & 36.2 & 972 & 6.33 & 4.47 & 36.2436 & 84 & 4.89 \\
\hline 302 & 211 & 2.32 & 03 & 13:42 & 3.08 & 35.8571 & 82 & 4.71 & 3.06 & 35.8 & 975 & 5.02 & 3.00 & 35.8563 & 038 & 3.35 \\
\hline 303 & 21137500 & 1.51 & $2000 / 12 / 06$ & 10:40 & 0.26 & 36.0103 & -120.5720 & 3.06 & 10.25 & 36.0115 & -120.5702 & 4.29 & 10.01 & 36.0026 & 5832 & 2.50 \\
\hline 304 & 21137763 & 2.91 & $2000 / 12 / 07$ & $15: 37$ & 6.06 & 36.2432 & -120.8031 & 6.02 & 26.04 & 36.2420 & 027 & 6.76 & 6.18 & 36.2399 & 125 & 4.50 \\
\hline 305 & 2113 & 1.29 & 07 & 17:16 & 6.93 & 36.2439 & -120. & 5.86 & 16.90 & 36.2452 & 995 & 6.63 & 46.89 & 36.2415 & 73 & 5.76 \\
\hline 306 & 21 & 1.13 & & $15: 47$ & 8.69 & 36.2089 & -12 & 5.87 & 38.72 & 36.2 & 383 & 6.14 & 38.89 & 36.1 & 96 & 3.37 \\
\hline 307 & 211 & 1.29 & & $22: 13$ & 4.44 & 36.2416 & -12 & 6.07 & 34.54 & 36.2 & 130 & 7.44 & 34.67 & 36.2217 & 60 & 9.00 \\
\hline 308 & 211 & 1.30 & 08 & $22: 29$ & 1.64 & 36.2416 & 14 & 5.99 & 11.63 & 36.2 & 00 & 6.60 & 1.80 & 36.2403 & 31 & 4.83 \\
\hline 309 & 2113 & 1.76 & 108 & $23: 52$ & 6.87 & 36.0857 & -12 & 3.26 & 56.88 & 36.0843 & 490 & 3.32 & 56.43 & 36.0690 & 662 & 4.24 \\
\hline 310 & 2113 & 1.32 & 109 & $13: 37$ & 6.00 & 36.2306 & -120 & 5.07 & 35.94 & 36.2308 & -120.7968 & 5.14 & 36.09 & 36.2288 & 945 & 2.92 \\
\hline 311 & 21 & 1.10 & 10 & $7: 59$ & 3.43 & 36.0094 & 08 & 2.63 & 3.45 & 36. & 685 & 3.75 & 3.08 & 36.0021 & 55 & 3.29 \\
\hline 312 & 211 & 1.42 & & $20: 27$ & 5.85 & 35.8024 & -12 & 9.69 & 55.88 & 35.8 & 33 & 9.64 & 55.93 & 35.8 & 52 & 8.99 \\
\hline 313 & 211 & 1.34 & 13 & 11:43 & 9.95 & 35.8707 & 12 & 11.25 & 29.81 & 35 & 37 & 12.09 & 29.45 & 35.8836 & 54 & 12.60 \\
\hline 314 & 2113 & 1.29 & $112 / 14$ & $3: 46$ & 6.81 & 36.0066 & 626 & 5.49 & 56.80 & 36.0070 & 630 & 5.79 & 56.21 & 35.9966 & 773 & 5.61 \\
\hline 315 & 211 & 1.49 & 115 & $2: 14$ & 6.35 & 36.2244 & -120 & 5.09 & 56.37 & 36.2 & 960 & 6.78 & 56.22 & 36.2179 & 982 & 8.81 \\
\hline 316 & 211 & 1.34 & $/ 12 / 15$ & 10:24 & 5.75 & 36.2243 & -120 & 5.14 & 15.87 & 36.2195 & 957 & 7.59 & 5.90 & 36.2161 & 962 & 5.30 \\
\hline 317 & 211 & 1.25 & & $21: 21$ & 0.90 & 36.2429 & -12 & 6.10 & 20.94 & 36.2 & 995 & 6.65 & 1.09 & 36.2427 & 47 & 5.20 \\
\hline 318 & 211 & 1.23 & 17 & $3: 90$ & 2.77 & 36.2714 & -12 & 7.22 & 22.73 & 36.2733 & 387 & 8.58 & 2.91 & 36.2688 & 416 & 5.36 \\
\hline 319 & 2113 & 1.34 & $/ 17$ & 17:60 & 2.03 & 36.0529 & -120 & 4.35 & 12.02 & 36.0562 & 015 & 4.39 & 1.53 & 36.0437 & 113 & 3.29 \\
\hline 320 & 21139420 & 1.10 & $2000 / 12 / 19$ & $3: 60$ & 0.54 & 36.0064 & -120.5653 & 4.23 & 0.58 & 36.0065 & 645 & 4.73 & 0.39 & 35.9979 & 704 & 2.83 \\
\hline 321 & 21139519 & 2.31 & $2000 / 12 / 19$ & $14: 58$ & 0.92 & 36.2404 & -120.8049 & 9.03 & 10.98 & 36.2402 & -120.8033 & 9.76 & 0.83 & 36.2378 & 169 & 9.21 \\
\hline 322 & 211 & 1.03 & $2 / 20$ & $4: 43$ & 8.48 & 36.0334 & & 4.98 & 58.49 & 36.0 & 348 & 4.42 & 8.29 & 36.0255 & 76 & 2.56 \\
\hline 323 & 3022 & 1.53 & 21 & $3: 45$ & 1.79 & 36.2427 & -120 & 6.12 & 51.84 & 36.2387 & 120 & 6.48 & $\$ 1.80$ & 36.2391 & 153 & 5.14 \\
\hline 324 & 21139926 & 1.33 & $2000 / 12 / 21$ & $4: 18$ & 6.91 & 36.2433 & -120.8040 & 6.08 & 56.99 & 36.2362 & -120.8128 & 6.63 & 56.82 & 36.2395 & -120.8064 & 5.79 \\
\hline 325 & 21140088 & 1.02 & $2000 / 12 / 21$ & $17: 24$ & 5.56 & 36.0324 & -120.5885 & 4.69 & 45.57 & 36.0345 & -120.5853 & 4.36 & 45.30 & 36.0240 & -120.5960 & 3.01 \\
\hline 326 & 21140267 & 2.73 & $2000 / 12 / 22$ & $23: 58$ & 0.02 & 36.0804 & -120.6322 & 4.74 & 0.16 & 36.0772 & -120.6375 & 5.05 & 0.18 & 36.0665 & -120.6509 & 4.33 \\
\hline 327 & 2114 & 1.52 & $2000 / 12 / 24$ & $0: 35$ & 7.20 & 36.1031 & -120.6770 & 3.05 & 37.25 & 36.1038 & -120.6765 & 3.25 & 36.53 & 36.0940 & 842 & 5.17 \\
\hline 328 & 2114 & 1.15 & $2000 / 12 / 24$ & 16:16 & 3.88 & 35.9836 & -120. & 2.46 & 33.92 & 35.9827 & -120 & 4.32 & 33.59 & 35.9764 & 506 & 0.69 \\
\hline 329 & 21140714 & 1.82 & $2000 / 12 / 25$ & $20: 47$ & 8.13 & 36.2220 & -120.7865 & 8.74 & 58.26 & 36.2180 & 7958 & 8.46 & 8.27 & 36.2175 & -120.7952 & 7.11 \\
\hline 330 & 21140776 & 1.31 & $2000 / 12 / 26$ & $8: 14$ & 1.50 & 36.0388 & -120.5935 & 4.79 & 51.45 & 36.0423 & -120.5868 & 4.76 & 1.23 & 36.0296 & -120.6033 & 0.90 \\
\hline 331 & 21141259 & 1.31 & $2000 / 12 / 29$ & $3: 52$ & 8.90 & 35.9243 & -120.4715 & 5.61 & 28.88 & 35.9257 & -120.4687 & 5.73 & 8.39 & 35.9218 & -120.4837 & 5.74 \\
\hline 332 & 2114 & 1.43 & $/ 12 / 30$ & $7: 51$ & 2.10 & 35.9602 & -120. & 10.91 & 22.06 & 35.9602 & -120.5082 & 10.97 & 2.26 & 35.9476 & 288 & 8.00 \\
\hline 333 & 21141944 & 1.32 & $2000 / 12 / 31$ & 6:10 & 9.84 & 36.2508 & -120.8149 & 5.26 & 39.95 & 36.2520 & -120.8143 & 6.86 & 10.12 & 36.2475 & -120.8165 & 4.06 \\
\hline
\end{tabular}

